\title{
La Denuncia de Tratados Internacionales de Derechos Humanos ${ }^{1}$
}

\author{
Daniela Salazar Marín \\ Universidad San Francisco de Quito
}

\begin{abstract}
Resumen
La ratificación de un tratado internacional de derechos humanos es considerada un acto ordinario de las relaciones internacionales de cada Estado. No obstante, la denuncia de un tratado internacional de derechos humanos es un acto de especial gravedad, y en consecuencia se encuentra revestido de límites derivados tanto del derecho internacional como del derecho interno de cada Estado. Este ensayo analiza tales límites y realiza un recuento de los contados casos de denuncia de tratados internacionales de derechos humanos con el afán de demostrar que no se trata de una facultad soberana que los Estados puedan ejercer sin restricciones. De manera particular se menciona el caso de Ecuador a raíz de las constantes amenazas de su gobierno de retirarse del Sistema Interamericano de Protección de Derechos Humanos.
\end{abstract}

\begin{abstract}
The ratification of international human rights treaties is considered an ordinary act of each State's international relations. However, the denunciation of an international human rights treaty is an act of particular gravity, and therefore limited by both international law and domestic law. This essay analyzes such limits and reviews the few cases of denunciation of international human rights treaties in an effort to demonstrate that it is not a sovereign power that States can exercise without restrictions. The case of Ecuador is examined in light of the constant threats from its government to withdraw from the Inter-American Human Rights Protection System.
\end{abstract}

Palabras Clave: Denuncia de Tratados / Derechos Humanos / Tratados Internacionales.

\section{Key Words}

Denunciation of Treaties / Human Rights / International Treaties.

Sumario. 1. Introducción 2. La facultad de denunciar tratados 2.1. Los límites derivados del Derecho Internacional 2.2. Los limitados casos de denuncia de tratados internacionales de derechos humanos 2.2.1. Tratados que permiten expresamente la denuncia 2.2.2. Tratados que no contienen cláusulas de denuncia 2.2.3. Denuncia de tratados con procedimientos jurisdiccionales optativos $\mathbf{2 . 2 . 4}$. Denuncia de tratados 
constitutivos de organizaciones con sistemas de protección de derechos humanos 2.2.5. La eventual denuncia de Ecuador a los Tratados del Sistema Interamericano de Derechos Humanos 2.3. Los límites derivados del derecho interno 3. Reflexiones finales sobre la denuncia de un tratado internacional de derechos humanos.

\section{Introducción}

La creciente tensión entre los gobiernos y las cortes internacionales de derechos humanos, así como también entre estas cortes y los tribunales internos, ${ }^{2}$ se ha traducido en amenazas por parte de los Estados para desvincularse de los sistemas internacionales de protección de derechos humanos. Las consecuencias del retiro de un Estado de los mecanismos de tutela de derechos humanos son nefastas, tanto para la universalización de la protección de los derechos, como para las víctimas de violaciones de derechos humanos, a quienes se les niega la posibilidad de encontrar justicia a nivel internacional cuando los tribunales internos incumplen su deber de proteger sus derechos. Por ello se vuelve imperioso revisar las normas y prácticas que rigen la denuncia de los tratados internacionales con miras a determinar si resulta viable o legítimo que los gobiernos denuncien los tratados que protegen derechos humanos.

En tanto la denuncia de un tratado internacional es el acto por medio del cual un Estado notifica su decisión de dar por terminadas las obligaciones internacionales adquiridas en el marco de tal tratado, podríamos considerarla un acto ordinario de gobierno en las relaciones internacionales de cada Estado. No obstante, la denuncia de un tratado internacional de derechos humanos es radicalmente distinta a la denuncia de un tratado bilateral de inversión o de cualquier otro tratado multilateral, cuyo objetivo no sea la protección de los derechos humanos. A continuación, examinaré el régimen particular de los tratados internacionales de derechos humanos, los contados casos de denuncia de tratados de derechos humanos, y los límites derivados del derecho internacional y del derecho interno para demostrar que, cuando de tratados internacionales de derechos humanos se trata, la denuncia constituye un acto no ordinario de las relaciones internacionales sujeto a limitaciones capaces de impedir que el Estado se desvincule de las obligaciones adquiridas por medio de tal tratado. El presente análisis incluye una referencia particular al caso de Ecuador.

\section{La facultad de denunciar tratados}

La participación de un Estado en un tratado internacional es un atributo esencial de la soberanía. En principio, cada Estado decide libremente si se vincula o se desvin-

2 Para un riguroso análisis de la tensión entre cortes internas y cortes internacionales de derechos humanos sugiero revisar: Huneeus, Alexandra, Courts Resisting Courts: Lessons from the Inter-American Court's Struggle to Enforce Human Rights, Cornell: Cornell Int'l L.J., 2000, p. 493. 
cula de un tratado internacional. Los tratados internacionales siguen un proceso de negociación entre los Estados Miembros de la organización auspiciante del tratado con miras a producir un texto aceptado por todos. Luego de esa negociación, cada Estado decide, en uso de su soberanía, si desea vincularse por las obligaciones del tratado. Para vincularse a un tratado internacional, el Estado debe expresar su consentimiento en obligarse por las disposiciones del tratado, lo que se produce generalmente a través de la firma ${ }^{3}$ y su posterior ratificación, o a través de la adhesión. Ambas medidas representan el compromiso, jurídicamente vinculante, de acatar las disposiciones del tratado.

Luego, para desvincularse de un tratado internacional, un Estado parte debe seguir las disposiciones relevantes de la Convención de Viena sobre el Derecho de los Tratados de 1969. Según el artículo 54 de esta norma, un Estado podría retirarse de un tratado: (a) conforme a las disposiciones del propio tratado relativas a la denuncia; (b) con el consentimiento de todas las partes después de consultar a todos los Estados contratantes; o (c) en el caso de un tratado que no contenga ninguna disposición sobre el retiro o la denuncia, dando un preaviso de al menos doce meses. Esta última posibilidad, según el artículo 56, está sometida a dos condiciones: (i) que se determine que fue intención de las partes admitir la posibilidad de denuncia o retiro; o (ii) que el derecho de denuncia o retiro pueda inferirse de la naturaleza del tratado. La carga de probar que se cumple una de estas dos condiciones recae sobre el Estado que desee retirarse de un tratado que no contenga disposiciones sobre denuncia.

La facultad de denunciar se justifica, entre otros, por la necesidad de motivar a más Estados a ratificar el tratado. No obstante, no puede asumirse que todo tratado puede ser denunciado. Se trata de una cuestión sujeta no sólo a la voluntad del Estado sino también a las normas del derecho internacional de los tratados y -según expondré más adelante- al derecho interno de cada Estado. A la luz de las normas de la Convención de Viena, resulta necesario examinar primero las disposiciones del propio tratado para determinar la voluntad de las partes de permitir la denuncia.

Un análisis de las cláusulas relativas a la denuncia de tratados internacionales de derechos humanos revela que no existe mayor uniformidad en sus textos. Así, es posible identificar: (i) tratados que permiten su denuncia en cualquier momento, esta-

\footnotetext{
$\overline{3 \text { La firma constituye una muestra }}$ de apoyo preliminar al tratado. Puede leerse como una indicación de que el Estado tiene intención de someter el tratado a un análisis nacional y considerará su ratificación. La firma sujeta a ratificación permite que cada Estado realice las gestiones pertinentes según las disposiciones de su derecho interno para que el tratado sea aprobado así como para adecuar su legislación interna a las obligaciones establecidas en el tratado. Aunque un Estado no está vinculado por las disposiciones de un tratado que firmó, a menos que esa firma esté seguida de una ratificación, está obligado a abstenerse de cualquier acto que ponga en peligro los objetivos y el propósito del tratado. Por su parte, la adhesión tiene los mismos efectos jurídicos que la ratificación, a pesar de no estar precedida de una firma.
} 
bleciendo únicamente un preaviso para que la denuncia surta efectos; ${ }^{4}$ (ii) tratados que permiten su denuncia, sujeta a ciertas condiciones; ${ }^{5}$ (iii) tratados que no tienen cláusulas para denunciar sus partes sustantivas pero contienen un artículo que permite denunciar sus procedimientos de protección; ${ }^{6}$ y (iv) tratados que no contienen cláusulas sobre denuncia. ${ }^{7}$

A pesar de la falta de uniformidad, la lectura de las cláusulas de denuncia de los tratados internacionales de derechos humanos mencionados en el párrafo anterior podría conducir a la conclusión de que un Estado puede desvincularse de los tratados internacionales de derechos humanos siempre y cuando su texto permita explícitamente su denuncia, mientras que, si ninguna disposición del tratado hace mención a la posibilidad de denunciarlo, bastaría con averiguar la intención de los otros Estados parte. Una conclusión de este tipo sería concordante con una interpretación textual de la Convención de Viena; no obstante, sería también ignorar que los tratados internacionales de derechos humanos tienen una naturaleza distinta a los demás tratados celebrados en el ámbito del derecho internacional público.

Los tratados de derechos humanos no son tratados bilaterales o multilaterales en los que los Estados intercambien compromisos recíprocos. En este tipo de tratados, los Estados asumen obligaciones de tutela de derechos humanos respecto de todas las personas bajo su jurisdicción. Los Estados, en tanto no son los beneficiarios de los derechos y obligaciones protegidos por este tipo de tratados, no están en capacidad de desvincularse de tales tratados; al menos no unilateralmente.

También por su naturaleza, la denuncia de un tratado de derechos humanos constituye una cuestión de extrema preocupación. Recordemos que los tratados de derechos humanos establecen la posibilidad de limitar los derechos reconocidos por sus disposiciones, permiten incluso la posibilidad de suspender esos derechos en situa-

\footnotetext{
4 Por ejemplo: Convención sobre los Derechos de las Personas con Discapacidad, Artículo 48; Protocolo Facultativo Primero del Pacto Internacional de Derechos Civiles y Políticos, Artículo 12.

5 Por ejemplo: Convención Americana sobre Derechos Humanos, Artículo 78 y el Convenio Europeo de Derechos Humanos, Artículo 15.

6 Por ejemplo: Convención contra la Tortura y Otros Tratos o Penas Crueles, Inhumanos o Degradantes, Artículo 31. Protocolo Facultativo de la Convención contra la Tortura y Otros Tratos o Penas Crueles, Inhumanos o Degradantes, Artículo 33. Convención sobre los Derechos del Niño, Artículo 52. Convención Internacional Sobre la Protección de los Derechos de Todos los Trabajadores Migratorios y de sus Familias, Artículo 89. Convención sobre los Derechos de las Personas con Discapacidad, Artículo 48. Protocolo Facultativo de la Convención Sobre los Derechos de las Personas con Discapacidad, Artículo 16. Protocolo Facultativo del Pacto Internacional de Derechos Económicos, Sociales y Culturales, Artículo 20. Convención Sobre la Eliminación de Todas las Formas de Discriminación Contra la Mujer, Artículo 19. Protocolo Facultativo Sobre la Participación de los Niños en los Conflictos Armados, Artículo 11. Protocolo Facultativo de la Convención Sobre los Derechos del Niño Relativo a la Venta de Niños, la Prostitución Infantil y la Utilización de Niños en la Pornografía, Artículo 15, entre otros.

7 Pacto Internacional de Derechos Civiles y Políticos; Convención Internacional para la protección de todas las personas contra las desapariciones forzadas; ; Carta Africana sobre Derechos Humanos y de los Pueblos y su Protocolo.
} 
ciones de emergencia, y otorgan a los Estados un margen de apreciación respecto de las medidas que deben adoptar para hacer efectivos los derechos. De ahí que únicamente circunstancias extraordinarias podrían justificar la necesidad de desvincularse del todo de las obligaciones asumidas en virtud de un tratado de derechos humanos.

En consecuencia, es más adecuado concluir que la denuncia de un tratado internacional de derechos humanos será posible no sólo de conformidad con las normas del mismo, sino también con su naturaleza y de acuerdo con la interpretación de los órganos de supervisión del tratado. Más allá de los límites derivados del propio derecho internacional, la denuncia de un tratado también está sujeta a límites establecidos en derecho interno de cada Estado. A continuación me referiré con más detalle a estas limitaciones derivadas tanto del derecho internacional como del derecho interno.

\subsection{Los límites derivados del Derecho Internacional}

Mencionaba previamente, que los beneficiarios de un tratado internacional de derechos humanos son los ciudadanos sometidos a la jurisdicción de ese Estado, y por tanto no se puede pretender aplicar a los tratados de derechos humanos las mismas reglas de derecho internacional público vigentes para un tratado bilateral o multilateral en el que los Estados intercambian beneficios recíprocos. Alguien podría rebatir esta idea bajo el argumento de que un tratado bilateral de inversión, por ejemplo, no sólo trae beneficios para los Estados sino también para los inversionistas. Pero lo cierto es que los tratados de inversión con frecuencia protegen la seguridad jurídica de los inversores incluso a costa de los derechos de los ciudadanos. De hecho, los casos de denuncia de tratados bilaterales de inversión evidencian que la motivación de tales denuncias subyace en la posible afectación a los intereses nacionales del Estado, generada por las millonarias demandas que enfrentan los Estados a causa del incumplimiento de las obligaciones asumidas para la protección de inversionistas extranjeros.

La naturaleza de los tratados internacionales de derechos humanos es distinta, y esto amerita un régimen particular para los casos de denuncia. En el año 1951, la Corte Internacional de Justicia (CIJ) se refirió por primera vez a esta particularidad al pronunciarse en una opinión consultiva sobre la Convención para la Prevención y Represión del Delito de Genocidio. Según la CIJ:

En tal convención los Estados contratantes no tienen intereses propios, tienen solamente, todos y cada uno de ellos, un interés común, que es el de preservar los fines superiores que son la razón de ser de la convención. En consecuencia, en una convención de este tipo no puede hablarse de venta- 
jas o desventajas individuales de los Estados, ni de mantener un equilibrio contractual exacto entre derechos y deberes. La consideración de los fines superiores de la Convención es, en virtud de la voluntad común de las partes, el fundamento y la medida de todas las disposiciones. ${ }^{8}$

En el mismo sentido, la Comisión Europea de Derechos Humanos en 1961 reconoció el carácter especial de estos tratados. Al referirse a las obligaciones asumidas por los Estados Partes del Convenio Europeo, señaló que tales obligaciones "son esencialmente de carácter objetivo, diseñadas para proteger los derechos fundamentales de los seres humanos de violaciones de parte de las Altas Partes Contratantes en vez de crear derechos subjetivos y recíprocos entre las Altas Partes Contratantes". ${ }^{9}$

El Tribunal Europeo de Derechos Humanos, refiriéndose a la especial naturaleza de estos tratados, señaló que:

[... ] al interpretar el Convenio debe atenderse a su naturaleza especial como tratado que instrumenta una garantía colectiva para el respeto de los derechos humanos y libertades fundamentales. En consecuencia, el objeto y fin del Convenio como instrumento de protección de seres humanos exige comprender y aplicar sus disposiciones de manera que haga efectivas y concretas aquellas exigencias. ${ }^{10}$

También la Corte Interamericana se ha referido al carácter especial de los tratados internacionales de derechos humanos, declarando que ciertas secciones de la Convención de Viena son inaplicables a la Convención Americana "entre otras razones, porque el objeto y fin de la Convención no son el intercambio recíproco de derechos entre un número limitado de Estados, sino la protección de los derechos de todos los seres humanos en América, independientemente de su nacionalidad". ${ }^{11}$ La Corte observó que los enunciados de la Convención de Viena "reflejan las necesidades de los tradicionales convenios multilaterales internacionales, que tienen por objeto un intercambio recíproco de derechos y obligaciones, para el beneficio mutuo de los Estados Partes". ${ }^{12}$ En este sentido, la Corte enfatizó:

\footnotetext{
8 Corte Internacional de Justicia, Reservas a la Convención para la Prevención y Sanción del Delito Genocidio, Opinión Consultiva de 28 de mayo de1951.

9Comisión Europea de Derechos Humanos. “Austria vs. Italy”, Application No. 788/60, European Yearbook of Human Rights, (1961), vol. 4, pág. 140.

10 Tribunal Europeo de Derechos Humanos. "Soering vs. United Kingdom”, Application No. 161, (1989) párrafo 87. En el mismo sentido, "Wemhoff vs. Germany”, Application No. 1936/63 (1968), vol. 7; "Ireland vs. United Kingdom”, Application No. 5310/71, (1978), vol. 25.

11 Corte IDH. "Otros Tratados" Objeto de la Función Consultiva de la Corte (art. 64 Convención Americana sobre Derechos Humanos). Opinión Consultiva OC-1/82 del 24 de septiembre de 1982. Serie A No. 1, párrafo. 27. 12 Ibídem, párr. 28.
} 
[...] los tratados modernos sobre derechos humanos, en general, y, en particular, la Convención Americana, no son tratados multilaterales de tipo tradicional, concluidos en función de un intercambio recíproco de derechos, para el beneficio mutuo de los Estados contratantes. Su objeto y fin son la protección de los derechos fundamentales de los seres humanos, independientemente de su nacionalidad, tanto frente a su propio Estado como frente a los otros Estados contratantes. Al aprobar estos tratados sobre derechos humanos, los Estados se someten a un orden legal dentro del cual ellos, por el bien común, asumen varias obligaciones, no en relación con otros Estados, sino hacia los individuos bajo su jurisdicción. ${ }^{13}$

Los órganos de supervisión de tratados del sistema universal también se han pronunciado en el mismo sentido. El Comité de Derechos Humanos, en su Observación General 26, consideró que el Pacto Internacional de Derechos Humanos, por su naturaleza, no es un tratado que entrañe un derecho de denuncia, en tanto los derechos consagrados en el Pacto corresponden a quienes viven en el territorio del Estado Parte de que se trate, protección que pasa a ser subsumida por el territorio al punto que las personas siguen siendo beneficiarias de ella con independencia de cualquier medida posterior que adopte el Estado Parte con el objeto de despojar a esas personas de los derechos que les garantiza el Pacto. ${ }^{14}$

Como consecuencia de la especial naturaleza de las obligaciones que los Estados asumen en virtud de la ratificación de tratados internacionales de derechos humanos, su facultad de denunciar estos tratados tiene límites que van más allá de los establecidos en la Convención de Viena para los tratados internacionales en general. A continuación expondré cómo los organismos de supervisión de los tratados de derechos humanos han resuelto los casos de denuncias a estos tratados considerándolas, en ciertas ocasiones, opuestas al objeto y fin del tratado y por tanto no válidas.

\subsection{Los limitados casos de denuncia de tratados internacionales de derechos humanos}

Los casos en los que un Estado ha tratado desvincularse de tratados internacionales de derechos humanos son tan escasos que bastaría enumerarlos para demostrar que este tipo de denuncia no constituye un acto ordinario de las relaciones internacio-

\footnotetext{
13 Ibídem, párr. 29. En el mismo sentido pueden entenderse los votos disidentes y razonados del Juez Antonio Cancado Trinidade cuando se refiere a la interpretación conforme con el carácter objetivo de las obligaciones convencionales contraídas por los Estados Partes en la Convención Americana.

14 CDH. Observación General No. 26, Comentarios generales adoptados por el Comité de los Derechos Humanos, Continuidad de las obligaciones, $6^{\circ}$ período de sesiones, U.N. Doc. HRI/GEN/1/Rev.7 (1997), párrafos. 3-5.
} 
nales de derechos humanos. Pero resulta aún más útil hacer un recuento de estos casos para determinar cómo el derecho internacional se ha activado -o no- para permitir o impedir tales denuncias. En esta sección examinaré los casos de tratados que contienen una cláusula que permite la denuncia, los casos de tratados que guardan silencio sobre la posibilidad de denunciar, los casos de denuncia de las cláusulas que establecen procedimientos jurisdiccionales optativos, y finalmente me referiré a la denuncia de los tratados constitutivos de organizaciones con sistemas de protección de derechos humanos.

\subsubsection{Tratados que permiten expresamente la denuncia}

El primer Estado en denunciar un tratado de derechos humanos fue Madagascar, que en 1965 notificó su decisión de retirarse de la Convención de las Naciones Unidas sobre el Estatuto de los Apátridas. Dicha Convención fue adoptada el 28 de septiembre de 1954 y entró en vigor el 6 de junio de 1960. Su artículo 40 establece la facultad de denunciar el tratado en cualquier momento, con un preaviso de un año. Este primer caso de denuncia de un tratado internacional de derechos humanos pasó desapercibido. Como apuntan Crawford y Lowe, "there was no controversy over this incident. Neither de depository of the instruments of signature/ratification/accession/denunciation nor any State party to the Convention sought to learn the reasons for denunciation. No one tried to bring Madagascar back into the fold of the Convention. Even the academic world ignored this incident". ${ }^{15}$ Dado que la Convención no establece un organismo encargado de supervisar el cumplimiento de las obligaciones adquiridas por los Estados parte, la denuncia entró en vigor sin pronunciamiento alguno respecto de su conformidad con el derecho internacional.

Dado que la Convención Americana sobre Derechos Humanos también permite expresamente su denuncia, esta sección incluye el análisis de los casos de Trinidad y Tobago y Venezuela, Estados que en 1998 y 2012, respectivamente, notificaron su decisión de desvincularse de este tratado. La Convención Americana sobre Derechos Humanos fue adoptada en 1969 y entró en vigor en 1978. Su artículo 78 establece la facultad de denunciar tratados con un preaviso de un año, y bajo la condición de que hayan transcurrido al menos cinco años a partir de la fecha de entrada en vigor de la misma.

El 26 de mayo de 1998, Trinidad y Tobago procedió a denunciar la Convención, denuncia que surtió efecto un año más tarde, el 26 de mayo de 1999. La denuncia tuvo lugar a raíz de que la Comisión y la Corte Interamericanas empezaran a conocer asuntos

15 Crawford, James y Vaughan Lowe. "The Denunciation of Human Rights Treaties". British Year Book of International Law (2008), págs. 156-157. 
relacionados con la aplicación de la pena de muerte en Trinidad y Tobago, requiriendo al Estado que tome las medidas necesarias para asegurar que las presuntas víctimas no sean privadas de la vida hasta que la Corte pueda examinar la pertinencia de las medidas provisionales solicitadas por la Comisión Interamericana de Derechos Humanos. ${ }^{16}$ La decisión de Trinidad y Tobago tiene como antecedente la sentencia del Comité Judicial del Consejo Privado en el caso Pratt y Morgan vs. Fiscal General de Jamaica.17 Según el Comité Judicial del Consejo Privado, cuyos estándares son obligatorios para Trinidad y Tobago, en los procesos de personas condenadas a pena muerte, si la ejecución tarda más de cinco años desde que se impone la pena capital, tal demora constituye un trato inhumano o degradante.

A raíz de ese estándar, el Fiscal General y el Ministro de Relaciones Exteriores de Trinidad y Tobago se reunieron con el Secretario General Adjunto de la Organización de los Estados Americanos (OEA) y con la Comisión Interamericana de Derechos Humanos (CIDH) para exponer los problemas que la demora del trámite de las peticiones ante los órganos internacionales de protección de los derechos humanos genera para el Estado. La Comisión señaló que tenía sus propios procedimientos establecidos para la consideración de peticiones, por lo que no podía garantizar que la consideración de los casos que conllevaran la aplicación de la pena capital se completaría dentro de un plazo específico.

El Gobierno de Trinidad y Tobago expresó que no estaba en condiciones de conceder que la incapacidad de la Comisión para tratar en forma expedita las peticiones relacionadas con casos de imposición de la pena de muerte frustre la ejecución de la sentencia, lo que acarrearía un incumplimiento con los estándares del Comité Judicial del Consejo Privado. El Estado de Trinidad y Tobago comunicó también a la Corte que no aceptaría responsabilidad alguna como consecuencia de la falta de la Comisión Interamericana para organizar sus procedimientos en relación con casos sometidos a ella de personas procesadas a pena de muerte dentro de los plazos establecidos en su derecho interno.

Por su parte, la Corte dejó "constancia de su preocupación debido a la denuncia de la Convención Americana que hiciera Trinidad y Tobago", añadiendo que tal decisión "no tiene precedentes en la historia del sistema interamericano de protección de derechos humanos". Adicionalmente, la Corte consideró que:

[... si bien la denuncia de un instrumento internacional es un derecho de los Estados Partes en él, en los tratados de derechos humanos, debido a

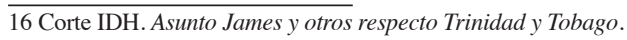

17 Comité Judicial del Consejo Privado en Pratt \& Morgan c. the Attorney General of Jamaica. 2 A.C.1. (1993) 
su especial naturaleza, esa denuncia afecta como un todo al sistema internacional o regional de derechos humanos de que se trate, lo cual, en este caso particular, justifica una gestión de parte de la Asamblea General de la Organización tendiente a obtener que Trinidad y Tobago reconsidere dicha decisión. ${ }^{18}$

No hubo ningún pronunciamiento de la Asamblea General al respecto. No existen registros de condenas públicas o intentos formales por parte de los otros Estados, tendientes a persuadir a Trinidad y Tobago de retirar su denuncia antes de que la denuncia se haga efectiva un año después, ni mayores esfuerzos para instar al Estado a volver a ratificar la Convención. Organizaciones de la sociedad civil, como Amnistía Internacional, alertaron sobre el efecto perjudicial de esta decisión e instaron al Estado a reconsiderar su decisión. ${ }^{19}$ También la Comisión de Derechos Humanos de la ONU urgió al gobierno de Trinidad y Tobago que reasuma las obligaciones adquiridas bajo la Convención Americana. ${ }^{20}$

En todo caso, la Corte IDH, a la luz de lo establecido en el artículo 78 de la Convención y el artículo 62.1 del mismo instrumento, siguió conociendo $\operatorname{casos}^{21}$ relacionados con hechos ocurridos mientras estuvo vigente la Convención en Trinidad y Tobago, así como también violaciones continuadas.

Como concluye Concepción, "in its attempt to speed up the process of carrying out local executions, Trinidad has virtually eliminated a significant mechanism that guarantees due process of law, namely the ability of its citizens to make complaints of human rights abuses to international bodies". ${ }^{22}$

Casi quince años transcurrieron desde la denuncia de Trinidad y Tobago sin que otro Estado pretenda desvincularse de la Convención Americana sobre Derechos Humanos. El 10 de septiembre de 2012, el Secretario General de la OEA recibió la nota formal de denuncia presentada por el Estado de Venezuela. ${ }^{23}$ La denuncia estuvo

\footnotetext{
18 Corte I.D.H. Informe Anual de la Corte Interamericana de Derechos Humanos, 1998, OEA/Ser.L/V/III.43 Doc. 11, págs. 35,36 y 37 .

19 Amnistía Internacional. Informe 1999. Pp. 332 y 333.

20 ONU. Consejo Económico y Social. Sub-Commission on the Promotion and Protection of Human Rights, Commission of Human Rights. Resolution 1999/5: Continuing of obligations under international human rights treaties. (E/CN.4/2000/2; E/CN.4/ Sub.2/1999/54). 31st meeting, 25 de agosto de 1999.

21 Corte I.D.H. Caso Hilaire, Constantine y Benjamin y otros Vs. Trinidad y Tobago. Sentencia de 21 de junio de 2002; Caso Caesar Vs. Trinidad y Tobago. Sentencia de 11 de marzo de 2005.

22 Concepción, Natasha Parassram. The Legal Implications of Trinidad \& Tobago's Withdrawal from the American Convention on Human Rights. 2001

23 Ministerio del Poder Popular para las Relaciones Exteriores. República Bolivariana de Venezuela. Nota 000125. Fecha 6 de septiembre de 2012.
} 
precedida de una serie de amenazas y antecedentes que permitían suponer que esto ocurriría.

De hecho, en diciembre de 2008, la Sala Constitucional del Tribunal Supremo de Justicia había solicitado al ejecutivo que se proceda a denunciar la Convención Americana. ${ }^{24}$ Esto sucedió en el marco de una acción de control de constitucionalidad presentada por abogados de la Procuraduría General en contra de una sentencia de la Corte Interamericana de Derechos Humanos que en ese año había ordenado a Venezuela reincorporar en sus cargos a los ex-magistrados de la Corte Primera de lo Contencioso Administrativo de Venezuela. ${ }^{25}$ La Sala Constitucional del Tribunal Supremo de Justicia consideró incompatibles los principios rectores de la Convención Americana con los establecidos en la Constitución Bolivariana de 1999, decidió que el fallo de la Corte era "inejecutable" y añadió: "se solicita al Ejecutivo Nacional proceda a denunciar este Tratado o Convención, ante la evidente usurpación de funciones en que ha incurrido la Corte Interamericana de los Derechos Humanos, con el fallo objeto de la presente decisión". ${ }^{26}$

Posteriormente, en febrero de 2010, en el marco de una rueda de prensa con corresponsales internacionales, y como reacción al informe "Democracia y Derechos Humanos en Venezuela" emitido por la Comisión Interamericana de Derechos Humanos, el Presidente Chávez anunció: "Vamos a prepararnos para denunciar el acuerdo a través del cual Venezuela se adscribió a esa nefasta Comisión Interamericana de Derechos Humanos y salirnos de ahí pues. ¿Pa' qué? No vale la pena, es una mafia lo que hay ahí".

La entonces Alta Comisionada de la ONU para los Derechos Humanos, Navi Pillay, instó enérgicamente a Venezuela a reconsiderar su decisión, advirtiendo que de concretarse su retiro, significaría un serio retroceso en la protección de los derechos humanos en Venezuela y en toda la región. Amnistía Internacional calificó a esta amenaza de denuncia como "una afrenta a las víctimas". ${ }^{27}$ También las organizaciones integrantes de la Coalición Internacional de Organizaciones por los Derechos Humanos

\footnotetext{
24 Sentencia N 1939 de la Sala Constitucional del Tribunal Supremo de Justicia de Venezuela (“TSJ”). 2008.

25 Corte IDH. Caso Apitz Barbera y otros ("Corte Primera de lo ContenciosoAdministrativo”) vs. Venezuela. Sentencia de 5 de agosto de 2008.

26 "Con fundamento en el principio de colaboración de poderes (artículo 136 de la Constitución de la República Bolivariana de Venezuela) y de conformidad con lo dispuesto en el artículo 78 de la Convención Americana sobre Derechos Humanos, se solicita al Ejecutivo Nacional proceda a denunciar este Tratado o Convención, ante la evidente usurpación de funciones en que ha incurrido la Corte Interamericana de los Derechos Humanos, con el fallo objeto de la presente decisión." Párrafo 2 de la decisión 1939/2008.

27 Amnistía Internacional: La ruptura de Venezuela con la corte regional de derechos humanos es "una afrenta a las víctimas" 13 septiembre 2012
} 
en las Américas lamentaron la noticia a través de un comunicado de prensa. ${ }^{28} \mathrm{~A}$ pesar de estas y otras reacciones que el solo anuncio de una eventual denuncia generó en la comunidad internacional, Venezuela decidió denunciar la Convención Americana en septiembre de 2012.

La nota mediante la cual Venezuela notificó la denuncia alega, entre otros motivos, la parcialidad de la Comisión Interamericana de Derechos Humanos, las dificultades para aprobar reformas al sistema interamericano de protección de derechos humanos, y los fundamentos de las decisiones de la Comisión y la Corte Interamericanas en contra de Venezuela. El pronunciamiento de la Cancillería establece que

[...] tanto la Comisión Interamericana de Derechos Humanos (CIDH) como la Corte Interamericana de Derechos Humanos (corte IDH), se han alejado de los sagrados principios que están llamados a proteger, convirtiéndose en un arma política arrojadiza destinada a minar la estabilidad de determinados gobiernos, y en especial al de nuestro país, adoptando una línea de acción injerencista en los asuntos internos de nuestro gobierno, vulnerando y desconociendo principios básicos y esenciales ampliamente consagrados en el derecho internacional. ${ }^{29}$

La comunicación agrega que ambas instituciones "se encuentran secuestradas por un pequeño grupo de burócratas desaprensivos que han bloqueado, obstaculizado e impedido que se hagan transformaciones necesarias" al sistema interamericano de derechos humanos, sistema que a su juicio "hoy día viola y transgrede con su mala práctica los principios del Pacto de San José y menoscaba, incluso, los derechos y obligaciones que sus Estados Parte han adquirido en el marco de la Carta de las Naciones Unidas". ${ }^{30}$

Al ser notificado de la decisión del Estado venezolano, el Secretario General emitió un tibio comunicado de prensa en el cual lamentó "la decisión adoptada por el gobierno de la República Bolivariana de Venezuela, de denunciar este instrumento jurídico, uno de los pilares de la normativa legal que ampara la defensa de los derechos humanos en el continente", y manifestó "su esperanza de que en el año que debe transcurrir para que dicha decisión se haga efectiva, como lo establece el Art.78, el

28 Coalición Internacional de Organizaciones por los Derechos Humanos en las Américas. Comunicado de Prensa: "Denuncia de Convención Americana sobre Derechos Humanos por Venezuela debilita protección de los derechos fundamentales de sus ciudadanos/as". 9 de septiembre de 2012.

29 Ministerio del Poder Popular para Relaciones Exteriores de la República Bolivariana de Venezuela. Nota 000125 de 6 de septiembre de 2012 .

30 Ibídem 
gobierno de la República Bolivariana de Venezuela pueda reconsiderar su decisión". ${ }^{31}$ Los Estados que pública y oficialmente deploraron la decisión fueron México, ${ }^{32}$ Paraguay $^{33}$ y Costa Rica ${ }^{34}$. La Comisión, a través del comunicado de prensa 117/12, informó que lamenta la decisión de Venezuela de denunciar la Convención. ${ }^{35}$ Por su parte, la Corte Interamericana no emitió comunicado alguno y, en sus informes anuales correspondientes a los años 2012 y 2013 se limitó a señalar los efectos de la denuncia de conformidad con el propio artículo 78 de la Convención, sin siquiera lamentar la decisión del Estado de Venezuela o instar al Estado a reconsiderar su decisión.

Mucho más alentadora fue la movilización de la sociedad civil venezolana frente a la denuncia. El 27 de septiembre de 2012 un amplio grupo de ciudadanos presentó ante la Sala Constitucional de Tribunal Supremo de Justicia una acción popular de inconstitucionalidad solicitando que se declare la nulidad por inconstitucionalidad del acto de gobierno a través del cual se denunció la CADH. Si bien el Tribunal tiene tres días para admitir una acción de esta naturaleza, hasta la fecha la acción no ha sido admitida. ${ }^{36}$

Mientras tanto en la OEA, más allá de las citadas reacciones por parte de México, Paraguay y Costa Rica, el silencio de los Estados en tanto creadores y garantes del sistema interamericano de protección de derechos humanos, fue patente. El año de preaviso transcurrió sin que los Estados de la OEA fueran capaces de generar una presión internacional que avergüence a Venezuela lo suficiente como para motivar que reconsidere su decisión.

Los discursos y esfuerzos son enfáticos en condenar y hasta ridiculizar a los Estados de la OEA que no han ratificado la Convención, pero ante un Estado que decidió desvincularse de este instrumento los Estados Miembros de la OEA se quedaron impávidos. Así, la denuncia por parte de Venezuela entró en vigor un año más tarde.

\footnotetext{
31Secretario General. Comunicado de prensa. C-307/12. https://www.oas.org/es/centro_noticias/comunicado_prensa. asp?sCodigo=C $-307 / 12$

32 Secretaría de Relaciones Exteriores. México. México lamenta la decisión de denunciar a la Convención Americana sobre Derechos Humanos. Comunicado 250.11 de septiembre de 2012. http://saladeprensa.sre.gob.mx/index.php/comunicados/1771-250 33Ministerio de Relaciones Exteriores de Paraguay. Comunicado de 13 de septiembre de 2012 en el que sostuvo que la medida "implica un retroceso en el largo camino que han forjado los pueblos de América en el reconocimiento de los derechos fundamentales de sus ciudadanos a través de su consagración en instrumentos como el Pacto de San José".

34Ministerio de Relaciones Exteriores de Costa Rica. Comunicado "Fortalecimiento SIDH" de 11 de septiembre de 2012 en el que el Canciller "deploró" la decisión de Venezuela de denunciar el Pacto de San José, y abogó porque Caracas pueda lo más pronto posible "reconsiderar la decisión" y adherirse nuevamente a la Convención Americana de Derechos Humanos.

35 CIDH. Comunicado de Prensa 117/12. CIDH lamenta decisión de Venezuela de denunciar Convención Americana sobre Derechos Humanos. 12 de septiembre del 2012.

36 Así lo aseguró Beatriz Borges, abogada representante de las organizaciones que elaboró el escrito presentado ante el Tribunal Supremo de Justicia.
} 
La CIDH reiteró su profunda preocupación ${ }^{37}$ y la Corte se limitó a dar cuenta de los efectos jurídicos de la denuncia en su informe anual.

Estos casos demuestran que cuando se produce una denuncia expresamente permitida por un tratado, el derecho internacional no ofrece mayor consuelo. El año de preaviso, establecido con el fin de movilizar a la comunidad internacional para evitar que la denuncia de un tratado de esta naturaleza se haga efectiva, no ha sido suficiente garantía al momento de evitar que un Estado se desvincule de sus obligaciones de protección en materia de derechos humanos.

Vale notar además que Convenciones ${ }^{38}$ de derechos humanos adoptadas con posterioridad a la denuncia de Trinidad y Tobago, así como Convenciones ${ }^{39}$ de derechos humanos adoptadas con posterioridad a la denuncia de Venezuela, han mantenido cláusulas que permiten su denuncia.

\subsubsection{Tratados que no contienen cláusulas de denuncia}

El Pacto Internacional de Derechos Civiles y Políticos (PIDCP) constituye el ejemplo más notable de un tratado internacional de derechos humanos que no contiene una cláusula expresa facultando a los Estados parte a denunciar el instrumento. A pesar de ello, dos Estados han pretendido desvincularse de sus obligaciones. El Pacto fue adoptado en 1966 y entró en vigor en 1976. El primer caso ocurrió en 1992, a raíz de que la República Federal de Yugoslavia (hoy Serbia y Montenegro) pretendió ser el Estado sucesor de la disuelta República Federal Socialista de Yugoslavia en 1992. En marzo de 1994, los Estados parte del PIDCP decidieron suspender a la República Federal de Yugoslavia de una reunión para elegir a los miembros del Comité de Derechos Humanos, órgano que supervisa el cumplimiento del citado Pacto. En respuesta, la República Federal de Yugoslavia decidió retirarse del Pacto. Sin embargo, la carta ${ }^{40}$ de notificación de esta decisión, fechada 26 de enero de 1995, no estuvo dirigida al Secretario General de la ONU, sino que se presentó al Presidente del Comité de Derechos Humanos.

37 CIDH. Comunicado de Prensa 64/2013. "CIDH manifiesta su profunda preocupación por efecto de la denuncia de la Convención Americana por parte de Venezuela". 10 de septiembre de 2013

38 Ver, por ejemplo, la Convención Interamericana para la Eliminación de Todas las Formas de Discriminación contra las Personas con Discapacidad. Artículo 13. 1999.

39 Ver, por ejemplo, la Convención Interamericana contra el Racismo, la Discriminación Racial y Formas Conexas de Intolerancia, Artículo 21; la Convención Interamericana contra toda Forma de Discriminación e Intolerancia, Artículo 21 y la Convención Interamericana sobre la Protección de los Derechos de las Personas Mayores, Artículo 39.

40 Consejo Económico y Social. Comisión de Derechos Humanos. $51^{\circ}$ período de sesiones. Tema 18 del programa provisional: "Carta de fecha 10 de enero de 1995 dirigida al Presidente de la Comisión de Derechos Humanos por el Embajador, Encargado de negocios interino de la República Federativa de Yugoslavia ante la Oficina de las Naciones Unidas en Ginebra”. E/CN.4/1995/130. 7 de febrero de 1995 
De hecho, la carta no menciona la palabra denuncia, tan sólo anuncia la decisión de la República Federal de Yugoslavia de no presentar más informes periódicos hasta ser tratado como un Estado parte. Al mismo tiempo, la nota menciona que el Estado no tenía intenciones de suspender las obligaciones sustantivas asumidas bajo el tratado. Dado que la presentación de informes periódicos es una obligación contenida en el Artículo 40 del Pacto, y una pieza clave del sistema de implementación del PIDCP, la decisión fue interpretada como una denuncia.

La decisión generaba un importante resquebrajamiento en el sistema de protección del Pacto y debilitaba la autoridad del Comité de Derechos Humanos en momentos de gran preocupación en materia de derechos humanos en la región de los Balcanes, provocada por una lucha interna de poderes entre los Estados Parte del Pacto. Lo que es peor, no hubo mayor reacción o condena por parte del Secretario General de la ONU, los Estados Parte del Pacto o la sociedad civil.

En 1999, bajo intervención de la OTAN, la situación en los Balcanes cambió drásticamente. El 1 de noviembre de 2000, cuando Yugoslavia entró a formar parte de la ONU como un nuevo miembro (bajo el nombre de Serbia y Montenegro), y renunció a tener continuidad de la personería de la ex Yugoslavia, esta primera suerte de denuncia del PIDCP quedó obsoleta. El 12 de marzo de 2001, Serbia y Montenegro ratificó el Pacto.

Un segundo caso de pretendida denuncia del PIDCP ocurrió en 1997 por parte de la República Popular Democrática de Corea. La República Popular Democrática de Corea ratificó el PIDCP en 1981, pero su pobre récord en materia de derechos humanos generó que sea objeto de constantes críticas. El 21 de agosto de 1997, la ex Sub Comisión para la Prevención de la Protección de las Minorías emitió una resolución ${ }^{41}$ sobre la situación de derechos humanos en la República Popular Democrática de Corea en la que, además de expresar preocupación por las persistentes alegaciones de graves violaciones a los derechos humanos, solicitaba al Estado enviar el informe periódico al que se refiere el artículo 40 del Pacto, respecto del cual el Estado estaba atrasado.En respuesta, en agosto del mismo año, la República Popular Democrática de Corea notificó su decisión de retirarse del PIDCP, acusando a la ex Sub Comisión de violar la soberanía y la dignidad del país. Afirmó que se veía obligado a retirarse del PIDCP porque "elementos deshonestos" estaban abusando de sus facultades, pero aclaró que continuaría garantizando plenamente los derechos contenidos en el tratado. 42

41 Consejo Económico y Social. Subcomisión de Prevención de Discriminaciones y Protección a las Minorías. Resolución de la Subcomisión 1997/3: Situación de los derechos humanos en la República Popular Democrática de Corea. E-CN_4-SUB_2RES-1997-3. 24 sesión, 21 de agosto de 1997.

42 Ver anexo a la Notificación del depositario C.N.467.1997.TREATIES-10. Disponible en: https://treaties.un.org/doc/ 
Al recibir la notificación, el Secretario General de la ONU envió una comunicación a la República Popular Democrática de Corea explicándole que el PIDCP no contiene una cláusula de denuncia y que, en consecuencia, sólo sería posible denunciar el tratado si todos los otros Estados Parte manifestaban estar de acuerdo con la denuncia. En consonancia con esta interpretación, el Secretario General circuló a los Estados la notificación de la República Popular Democrática de Corea junto con su nota de respuesta. ${ }^{43}$ Ciertos Estados se opusieron a la denuncia, sin que se haya producido una resolución formal al respecto.

A mes seguido, en septiembre de 1997, en el marco de una reunión de los presidentes de los órganos de tratado de la ONU en ginebra, el presidente del Comité de Derechos Humanos tomó la oportunidad para provocar una respuesta colectiva de estos organismos. En una resolución, los presidentes de los órganos de tratado manifestaron su profunda preocupación por la denuncia, cuestionaron seriamente la legalidad del procedimiento seguido, y se opusieron a la posibilidad de que una denuncia pueda producirse de manera unilateral. Adicionalmente, hicieron un llamado a la comunidad internacional a hacer todo lo posible para mantener la integridad del sistema de tratados de derechos humanos de la ONU. Los Estados no reaccionaron.

Así las cosas, pudo haberse generado un reconocimiento de la facultad de los Estados de denunciar tratados de derechos humanos que no contienen cláusulas sobre denuncia, bajo la condición de que ningún otro Estado Parte se oponga. Pero los miembros del Comité de Derechos Humanos supieron actuar con firmeza y celeridad. En octubre de 1997, el Comité de Derechos Humanos sesionó y, a la luz de la facultad establecida en el artículo 40 párrafo 4 del PIDCP, adoptó su Observación General 26.44 En esta decisión, el Comité, en tanto intérprete último del Pacto, estableció que el derecho internacional no permite que un Estado denuncie el PIDCP o se separe de él, ni aún con la aquiescencia de todos los Estados Parte, según había señalado el Secretario General de la ONU en su comunicación a los Estados.

La Comisión de Derechos Humanos de la ONU, que aún existía, apoyó las conclusiones del Comité de Derechos Humanos. El 22 de octubre de 1999, ${ }^{45}$ el Comité de Derechos Humanos reiteró a la República Popular Democrática de Corea su solicitud

\footnotetext{
Publication/CN/1997/CN.467.1997-Eng.pdf

43 Notificación del depositario C.N.467.1997.TREATIES-10. Disponible en: https://treaties.un.org/doc/Publication/CN/1997/ CN.467.1997-Eng.pdf

44 CDH. Observación General No. 26, Comentarios generales adoptados por el Comité de los Derechos Humanos, Continuidad de las obligaciones, $6^{\circ}$ período de sesiones, U.N. Doc. HRI/GEN/1/Rev.7 (1997), párrafos. 2-5.

45 Informe periódico de la República de Corea (CCPR/C/114/Add.1) en sus sesiones 1791 a y 1792 (véase CCPR/C/SR.1791 y SR.1792), , y aprobó las siguientes observaciones finales en su 1802 a sesión (CCPR/C/SR.1802), celebrada el 29 de octubre de 1999.
} 
de informe periódico y, en mayo de 2000, el Estado sometió su segundo informe periódico al Comité, el mismo que fue conocido el en julio de 2001.46 El informe fue valorado por el Comité, que lo tomó como una oportunidad para restablecer el diálogo con el Estado, que se había quebrado desde 1984. Si bien la República Popular Democrática de Corea no retiró formalmente su pretendida denuncia al Pacto, esta se interpretó como no presentada.

Durante los casi tres años transcurridos desde la pretendida denuncia hasta la presentación del informe periódico por parte de la República Popular Democrática de Corea, el Comité de Derechos Humanos, en tanto órgano encargado de la supervisión del cumplimiento del Pacto, jugó un rol fundamental y protagónico que contrastó con la incapacidad de reacción de los otros Estados y la desatinada respuesta del Secretario general de la ONU. Similares organismos de protección creados por los tratados de derechos humanos deberían mirar como un ejemplo al Comité de Derechos Humanos, cuya oportuna reacción logró impedir que la denuncia de la República Popular Democrática de Corea al PIDCP se haga efectiva.

La Observación General del Comité de Derechos Humanos no sólo respondió a las pretensiones de la República Popular Democrática de Corea sino que envió un mensaje contundente aclarando a otros Estados Parte del PIDCP que la denuncia del Pacto no está permitida. La ausencia de una norma que expresamente permita la facultad de denunciar el Pacto no es una cuestión gratuita, por el contrario, es significativa. Tal omisión da cuenta que la intención del tratado fue impedir que unilateralmente se desconozcan obligaciones asumidas en favor de los ciudadanos. En palabras del Comité, "los redactores del Pacto tuvieron el propósito deliberado de excluir la posibilidad de denuncia. Se llega a esa misma conclusión respecto del Segundo Protocolo Facultativo, en el que se omitió deliberadamente la inclusión de una cláusula de denuncia". ${ }^{47}$

Lo que es más, la decisión del Comité ha servido y servirá para guiar la interpretación de otros organismos de protección en relación con tratados que guardan silencio respecto de la facultad de denunciar. Así, por ejemplo, los tratados de derechos humanos adoptados en el marco de la Organización de la Unidad Africana y su sucesora, la Unión Africana, no contienen una cláusula de denuncia. ${ }^{48}$ Si bien no hay casos

\footnotetext{
46 Informe periódico de la República de Corea (CCPR/C/PRK/2000/2) en sus sesiones 1944a a 1946a , celebradas los días 19 y 20 de julio de 2001

47 CDH. Observación general N ${ }^{\circ} 26$. Comentarios generales adoptados por el Comité de los Derechos Humanos, Continuidad de las obligaciones, $66^{\circ}$ período de sesiones, U.N. Doc. HRI/GEN/1/Rev.7 (1997), párrafo 2.

48La excepción a esta regla la constituye la Convención de Kampala sobre Desplazados Internos de 2009 que permite una denuncia motivada con un preaviso de un año. Artículo 19.
} 
de denuncia a la Carta Africana de Derechos Humanos y de los Pueblos, la decisión del Comité de Derechos Humanos constituye un fundamento para sostener que no sería viable denunciar este tratado en tanto no contiene una cláusula de denuncia. Lo mismo podríamos sostener respecto de otros tratados de derechos humanos celebrados en el marco de la ONU que guardan silencio sobre la facultad de denunciar, como el Pacto Internacional de Derechos Económicos, Sociales y Culturales de 1966, la Convención para la Eliminación de la Discriminación contra la Mujer de 1979, o el Protocolo para la abolición de la Pena de Muerte de 1989. En el mismo sentido, podríamos entender que no están permitidas las denuncias de los dos Protocolos a la Convención Americana sobre Derechos Humanos (el de Derechos Económicos, Sociales y Culturales de 1988 y el de Abolición a la Pena de Muerte de 1990), en tanto ninguno de ellos establece expresamente la facultad de denunciar.

Sin embargo, la interpretación de que está prohibida la denuncia de todo tratado que no lo permita de manera explícita no es unívoca. Parecería que a juicio de la Comisión Africana de Derechos Humanos resulta necesario atender a la intención de los Estados Partes de permitir la denuncia de la Carta Africana de Derechos Humanos y de los Pueblos. La Comisión examinó un caso en el que consideró decretos adoptados por el gobierno militar de Nigeria con miras a anular los efectos internos de la Carta Africana de Derechos Humanos, y en su decisión señaló:

Given that Nigeria ratified the African Charter in 1983, it is presently a convention in enforce in Nigeria. If Nigeria wished to withdraw its ratification, it would have to undertake an international process involving notice, which it has not done. Nigeria cannot negate the effects of its ratification of the Charter through domestic action. ${ }^{49}$

El lenguaje sugiere que la Comisión Africana admite que una denuncia a la Carta es posible, aunque no esté expresamente permitida, siempre y cuando se cumplan las formalidades del procedimiento de denuncias.

\subsubsection{Denuncia de tratados con procedimientos jurisdiccionales optativos}

La mayoría de casos de denuncia de tratados de derechos humanos está relacionada con la intención de evitar el control judicial o cuasi-judicial internacional previsto en tales tratados. Así lo reconoció el Alto Comisionado de Naciones Unidas para los Derechos Humanos en su resolución de 1999 sobre la continuidad de las obligaciones

49 Comisión Africana de Derechos Humanos. Civil Liberties Organization v. Nigeria, Comunicación No. 129/94 (1995), párrafo 13. 
establecidas en los tratados internacionales de derechos humanos. ${ }^{50} \mathrm{Si}$ bien la resolución admite que el retiro de un mecanismo de protección de derechos humanos será legal o no de conformidad con las disposiciones del tratado en cuestión, observó que en la práctica las denuncias ocurren como consecuencia de decisiones en las que los mecanismos de protección de derechos establecidos por tales tratados determinan la responsabilidad internacional de los Estados.

Con frecuencia, los tratados internacionales de derechos humanos establecen procedimientos facultativos que permiten a los organismos de supervisión de cada tratado conocer peticiones o denuncias individuales en las que se alega que un Estado violó las obligaciones adquiridas en el marco del tratado. Así, no basta con que el Estado ratifique el tratado para que un individuo pueda presentar denuncias contra ese Estado, sino que el Estado debe realizar pasos adicionales para que los organismos de protección tengan competencia para conocer casos y determinar la responsabilidad internacional de un Estado en particular. Por ejemplo, no basta con ser un Estado Parte de la Convención Americana sobre Derechos Humanos sino que, de conformidad con el Artículo 62 de la Convención, es necesario que los Estados depositen un instrumento de ratificación de la competencia contenciosa de la Corte Interamericana. De manera similar, el Pacto Internacional de Derechos Civiles y Políticos y el Pacto Internacional de Derechos Económicos, Sociales y Culturales de la ONU, no contemplan entre sus disposiciones mecanismos de denuncia individual ante sus respectivos Comités. Es necesario que los Estados ratifiquen los Protocolos Facultativos para otorgar a los Comités la competencia de conocer comunicaciones individuales contra un Estado. Resulta necesario entonces determinar cómo ha operado en la práctica la denuncia de los tratados internacionales de derechos humanos cuyos procedimientos jurisdiccionales son optativos.

El primer caso ocurrió en 1997 cuando Jamaica denunció el Protocolo Facultativo del Pacto Internacional de Derechos Civiles y Políticos. El Protocolo tiene por objetivo facultar al Comité de Derechos Humanos (creado por el Pacto) para recibir y considerar comunicaciones de individuos que aleguen ser víctimas de violaciones de cualquiera de los derechos enunciados en el Pacto. El artículo 12 del Protocolo Facultativo permite expresamente que los Estados Parte denuncien el Protocolo en cualquier momento, y establece que la denuncia surtirá efecto tres meses después de la fecha en que el Secretario General haya recibido la notificación. Además establece que la denuncia no afecta a las comunicaciones presentadas antes de la fecha de efectividad de la denuncia.

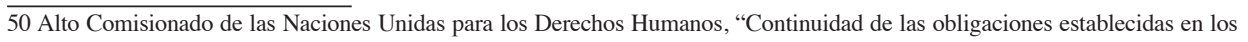
tratados internacionales de derechos humanos”. Sub Comité. Resolución 1999/5, 25 de agosto de 1999. 
La denuncia de Jamaica estuvo precedida por denuncias de cientos de personas condenadas a pena de muerte, y decisiones reiteradas del Comité de Derechos Humanos en las que este organismo determinó la responsabilidad internacional del Estado de Jamaica y recomendó la liberación de los condenados y su reparación.

No es posible comprender esta denuncia, así como las posteriores denuncias de Guyana y Trinidad y Tobago, sin referirnos a la decisión del caso Pratt and Morgan. Recordemos que, si bien los Estados angloparlantes del Caribe se independizaron del Reino Unido en la década de los 60, mantienen hasta ahora vínculos jurídicos con ese país. Tal es así que la más alta corte de apelaciones para estos países continúa siendo el Judicial Committee of The Privy Council (JCPC), una institución que remonta sus orígenes a la conquista normanda. Los miembros del Consejo eran asesores de la Corona y actuaban bajo la premisa de que "el Rey es la fuente de toda justicia en todos sus dominios". Hoy en día, los miembros del JCPC son jueces británicos de la Casa de los Lores.

En 1993, el JCPC se refirió al fenómeno de la pena de muerte en el caso Pratt v. Attorney-General for Jamaica. El caso no cuestionaba la pena de muerte en sí, sino que alegaba que los extensos períodos de detención de los condenados a pena de muerte constituían tratos o penas crueles y degradantes, prohibidos constitucional e internacionalmente. Earl Pratt e Ivan Morgan habían sido condenados a pena de muerte en 1979, a esta condena le sucedieron una serie de apelaciones internas e internacionales, tanto ante la Comisión Interamericana de Derechos Humanos como ante el Comité de Derechos Humanos. En 1986, el Comité emitió una medida interina de protección solicitando que Jamaica se abstenga de ejecutar a Pratt y Morgan hasta que el Comité pueda revisar sus denuncias. En 1988, el Comité declaró admisibles las peticiones, y su decisión sobre el fondo recién fue emitida en 1989.

Al tiempo, las apelaciones internas provocaron que el JCPC conozca los casos de Pratt y Morgan en 1993, más de 14 años después de su condena. El JCPC condenó el sistema de apelaciones que permitía que se dilate la ejecución de la condena por tantos años y señaló que una demora mayor a cinco años en ejecutar a una persona condenada a pena de muerte sería inconstitucional. A juicio del JCPC, los cinco años eran suficientes para agotar recursos internos y obtener decisiones de organismos internacionales. Ejecutar a los señores Pratt y Morgan después de más de una década de mantenerlos en el corredor de la muerte constituía, según el JCPC, un trato cruel e inhumano.

En consecuencia, las instancias internacionales se convirtieron en un obstáculo para que Jamaica y los países del Caribe puedan ejecutar a los condenados a pena de 
muerte dentro del plazo máximo de cinco años fijado por el Comité. Jamaica procuró un acercamiento a la Comisión Interamericana y al Comité de Derechos Humanos para que estos organismos decidan los casos de pena de muerte en un período inferior a siete meses. Como consecuencia de la negativa de estos organismos a aceptar tales condiciones, incompatibles con sus procedimientos internos así como con sus recursos humanos y financieros, el 23 de octubre de 1997 Jamaica denunció el Protocolo Facultativo al PIDCP, desterrando el derecho de los individuos a presentar peticiones ante el Comité de Derechos Humanos. No fue necesario que Jamaica denunciara también la Convención Americana sobre Derechos Humanos en tanto nunca depositó su instrumento de ratificación de la competencia contenciosa de la Corte. Cabe notar que el Comité continuó conociendo casos que habían sido presentados antes de la denuncia de Jamaica, y por ello continuó participando de estos procedimientos en reconocimiento de que la denuncia no tiene un efecto retroactivo.

En tanto las decisiones del JCPC constituyen un precedente obligatorio para otros Estados sometidos a su jurisdicción, la decisión del caso Pratt and Morgan motivó a que el 26 de mayo de 1998 Trinidad y Tobago denuncie tanto el Protocolo Facultativo al PIDCP como la Convención Americana sobre Derechos Humanos. Una vez hecha efectiva la denuncia al Protocolo Facultativo, lo ratificó nuevamente, pero esta vez con una reserva dirigida a impedir que el Comité de Derechos Humanos revise peticiones de condenados a pena de muerte. En noviembre de 1999, el Comité de Derechos Humanos declaró admisible una petición presentada por un condenado a pena de muerte en Trinidad y Tobago, declarando que tal reserva era incompatible con el objeto y fin del tratado. ${ }^{51}$

En consecuencia, Trinidad y Tobado denunció nuevamente el Protocolo Facultativo el 27 de marzo de 2000, constituyéndose en el único Estado que ha denunciado un tratado de derechos humanos en dos ocasiones. Por su parte, Guyana, si bien no estaba vinculada por las decisiones del JCPC, denunció el Protocolo Facultativo el 5 de enero de 1999 como reacción a la primera decisión del Comité de Derechos Humanos contra Guyana, en la que el Comité recomendó que dos condenados a pena de muerte sean liberados ${ }^{52}$. El gobierno consideró esta decisión una violación a la soberanía nacional, denunció el protocolo y luego lo ratificó nuevamente con una reserva idéntica a la que había presentado Trinidad y Tobago, con el fin de impedir que el Comité conozca casos de condenados a pena de muerte. El Comité de Derechos Humanos ha

51 CDH. Caso "Rawle Kennedy vs. Trinidad y Tobago". Communication No. 845/1998, U.N. Doc. CCPR/C/74/D/845/1998 (2002). 52Dictámenes del Comité a tenor del artículo 5, párrafo 4, del Protocolo Facultativo Comunicación No 812/1998. 
recomendado a Guyana que retire la reserva formalmente ${ }^{53}$, sin que el Estado haya cumplido esta recomendación.

La reacción de otros Estados Parte del PIDCP frente a estas denuncias fue casi nula. Tampoco existen nuevas iniciativas estatales para promover una nueva ratificación del Protocolo por parte de Estos países. La sociedad civil, sobre todo a nivel de organizaciones internacionales de derechos humanos como Amnistía Internacional, condenó fuertemente las denuncias, pero tal condena no fue suficiente para impedir que se hagan efectivas. El Comité de Derechos Humanos a través de sus informes periódicos hizo llamados para que se retiren las denuncias, también sin éxito. ${ }^{54}$ Curiosamente, lo que sí generó una reacción de rechazo por varios Estados Parte, fue la reserva introducida con ocasión de la ratificación del Protocolo Facultativo con ocasión de su segunda ratificación por parte de Trinidad y Tobago así como Guyana. Si bien los otros Estados no son los que determinan la validez de las denuncias o reservas, Finlandia, Francia, Países Bajos, Polonia, España, Suecia y otros consideraron que el derecho internacional de los derechos humanos impide realizar reservas posteriores a la ratificación, de tal forma que la práctica de denunciar un instrumento con el único fin de volverlo a ratificar para presentar una reserva sentaba un fatal precedente para el derecho de los tratados.

Por parte de la academia, la denuncia de los tratados internacionales de derechos humanos por parte de estos tres Estados del Caribe ha sido vista como una consecuencia del aumento en la legalización y judicialización del derecho internacional, cuyos procedimientos cuasi-judiciales y judiciales son cada vez más complejos y lentos ${ }^{55}$.

El caso de Perú es similar a los anteriores, en tanto se produjo como consecuencia de decisiones de la Corte Interamericana que incomodaron al gobierno de Alberto Fujimori. El 30 de mayo de 1999, la Corte Interamericana dictó sentencia en el Caso Castillo Petruzzi y otros contra el Perú. ${ }^{56}$ En dicha decisión, la Corte encontró al Perú responsable por la violación de diversas disposiciones de la Convención Americana y ordenó, entre otros, que se garantice a las víctimas un nuevo juicio en plena observancia de su derecho al debido proceso. De manera inmediata, el entonces Presidente Fujimori anunció que no cumpliría la sentencia. Casi al mismo tiempo, el

\footnotetext{
53 Comité de Derechos Humanos, Comentario General 24(13). En el mismo sentido, Comité de Derechos Humanos, Comentario General 24(8).

54 Segundo Informe Periódico del Comité de Derechos Humanos respecto de Jamaica. 1997. CCPR/C/42/Add.15. http:// tbinternet.ohchr.org/_layouts/treatybodyexternal/Download.aspx?symbolno=CCPR\%2FC\%2F42\%2FAdd.15\&Lang=en.

55 Helfer, Laurence R., Over legalizing Human Rights: International Relations Theory and the Commonwealth Caribbean Backlash Against Human Rights Regimes. Columbia Law Review, Vol. 102, November 2002; Vanderbilt Public Law Research Paper No. 06-05; Loyola-LA Legal Studies Paper No. 2002-13

56Corte IDH. Caso Castillo Petruzzi y otros vs. Perú. Sentencia de 30 de mayo de 1999 (Fondo, Reparaciones y Costas)
} 
14 de junio de 1999, la Corte Suprema de Justicia de Perú declaró inejecutable ${ }^{57}$ la sentencia sobre reparaciones que el 27 de noviembre de 1998 había emitido la Corte Interamericana en el caso Loayza Tamayo. ${ }^{58}$

El primero de julio de 1999, el Estado de Perú presentó ante el Secretario General de la OEA un documento titulado "Resumen de la posición del Estado peruano ante la OEA, sobre la sentencias emitidas por la Corte IDH en los casos Castillo Petruzzi y Loayza Tamayo", 59 explicando las razones en virtud de las cuales no cumpliría las decisiones del tribunal interamericano. Siete días más tarde, el Congreso peruano aprobó por 66 votos a favor, 33 en contra y una abstención un proyecto impulsado por el Presidente Fujimori mediante el cual se decidió el "retiro, con efecto inmediato, del reconocimiento de la competencia contenciosa de la Corte Interamericana de Derechos Humanos"..$^{60}$ La decisión, que no implicaba una denuncia de la Convención Americana sino únicamente un desconocimiento de la facultad contenciosa de la Corte, fue notificada al Secretario General de la OEA el 9 de julio de 1999.

No obstante, el 24 de septiembre de 1999, la Corte Interamericana dictó una sentencia sobre competencia en la que resolvió que "es inadmisible el pretendido retiro por el Perú de la declaración de reconocimiento de la competencia contenciosa de la Corte con efectos inmediatos, así como cualesquiera consecuencias que se busque derivar de dicho retiro, entre ellas, la devolución de la demanda, que resulta irrelevante". ${ }^{61}$ La Corte recordó que un Estado parte sólo puede desvincularse de sus obligaciones atendiendo a las disposiciones del propio tratado, y señaló que la Convención Americana sobre Derechos Humanos establece la posibilidad de denunciar todo el tratado, pero no prevé explícitamente el retiro del reconocimiento de la competencia contenciosa de la Corte. Al no existir una cláusula expresa que permita retirar la declaración que reconoce la competencia contenciosa de la Corte, el Tribunal consideró que el pretendido retiro de Perú de la competencia contenciosa de la Corte era incompatible con el objeto y fin de la Convención.

Posteriormente, la caída del régimen de Fujimori favoreció las condiciones políticas para dejar sin efecto la pretendida denuncia de Perú al procedimiento contencio-

\footnotetext{
57 Resolución del Pleno del Tribunal Constitucional de Perú. 31 de agosto de 2009. EXP. N. ${ }^{\circ}$ 04063-2007-PA/TC 58 Corte IDH. Caso Loayza Tamayo Vs. Perú. Sentencia de 27 de noviembre de 1998 (Reparaciones y Costas)

59 Representación Permanente del Estado de Perú ante la OEA. Posición del gobierno peruano ante los fallos de la Corte Interamericana de Derechos Humanos. 1 de julio de 1999.

60 Congreso de la República de Perú. Resolución Legislativa n’o 27152. Citada por: Dulitzky, Ariel. El retiro del reconocimiento de la competencia contenciosa de la Corte Interamericana de Derechos Humanos por parte de Perú. Análisis Jurídico. Pensamiento Constitucional. Año VI No. 6.

61 Corte IDH. Caso Ivcher Bronstein Vs. Perú. Sentencia de 24 de septiembre de 1999 (Competencia); Caso del Tribunal Constitucional Vs. Perú Sentencia de 31 de enero de 2001. Párr. 36.
} 
so de la Corte Interamericana. El 12 de enero de 2000, el Congreso de la República acordó, ${ }^{62}$ derogar la resolución legislativa a través de la cual se había decidido retirar el reconocimiento de la competencia contenciosa de la Corte, así como encargar al poder ejecutivo realizar las acciones necesarias para dejar sin efecto los resultados que habría generado tal resolución. El 29 de enero de 2001, el Estado de Perú notificó al Secretario General de la OEA que el reconocimiento de la competencia contenciosa de la Corte Interamericana de Derechos Humanos, efectuado por Perú el 20 de octubre de 1980, se encontraba plenamente vigente y comprometía al Estado peruano de manera ininterrumpida desde el depósito de la declaración de reconocimiento de la competencia contenciosa de la Corte realizado el 21 de enero de 1981. Así, vale decir que Perú no denunció la Convención Americana y su pretensión de denunciar el procedimiento facultativo que otorga competencia contenciosa a la Corte fue considerada inválida tanto por la propia Corte como por el gobierno que sucedió al régimen de Fujimori.

Finalmente, la sección relativa a denuncias de tratados con procedimientos jurisdiccionales optativos no estaría completa sin una mención a la denuncia de Estados Unidos al Protocolo Facultativo sobre la Jurisdicción Obligatoria para la Solución de Controversias de la Convención de Viena sobre Relaciones Consulares de 1961. Si bien la Convención de Viena sobre Relaciones Consulares no es propiamente de un tratado de derechos humanos, ni puede decirse que el objetivo del tratado como un todo sea la protección de los derechos humanos, la Corte Interamericana ha establecido que algunas de sus disposiciones conciernen a los derechos humanos, en tanto reconocen el derecho del nacional del Estado que envía para acceder al funcionario consular con el fin de procurar asistencia consular en el Estado receptor. ${ }^{63}$ El Protocolo Facultativo a esta Convención otorga a la Corte Internacional de Justicia jurisdicción para decidir quejas entre Estados Parte de la Convención de Viena sobre relaciones consulares.

En marzo de 2005, Estados Unidos denunció el Protocolo luego de que la Corte Internacional de Justicia lo declare internacionalmente responsable por la violación del derecho de notificación consular en varios casos. ${ }^{64}$ Ahora bien, el Protocolo no contiene una cláusula que expresamente permita su denuncia. En consecuencia, a la luz de la jurisprudencia establecida en los casos citados previamente en este ensayo, implica que la denuncia no está permitida, es contraria al objeto y fin del tratado y

\footnotetext{
62 Congreso de la República de Perú. Resolución Legislativa № 27401.

63 Corte IDH. Opinión Consultiva OC-16/99. 1 de octubre de 1999, solicitada por los Estados Unidos Mexicanos. Párr. 2.

64 En relación con la denuncia de Estados Unidos al Protocolo Facultativo sobre la Jurisdicción Obligatoria para la Solución de Controversias de la Convención de Viena sobre Relaciones Consulares, véase: Quigley, John. The United States' Withdrawal from International Court of Justice Jurisdiction in Consular Cases; Reasons and Consequences.
} 
debería declararse inválida por parte del órgano a cargo de la supervisión del tratado, esto es, la Corte Internacional de Justicia. No obstante, no ha existido un pronunciamiento de la Corte Internacional de Justicia al respecto, ni los Estados han reaccionado condenando esta pretendida denuncia, quizá porque Estados Unidos de todas maneras no cumplía las decisiones de esta Corte respecto del derecho de notificación consular. Llama la atención también la poca atención que esto suscitó en la sociedad civil estadounidense, considerando que uno de los efectos de esta denuncia, si fuera válida, es que Estados Unidos no podría demandar a otro Estado si ese otro Estado viola el derecho de notificación consular de un estadounidense detenido en el Estado receptor. Resultaría interesante que un Estado demande nuevamente a Estados Unidos ante la Corte Internacional de Justicia con base en el Protocolo Facultativo sobre la Jurisdicción Obligatoria para la Solución de Controversias de la Convención de Viena sobre Relaciones Consulares, para que la Corte pueda pronunciarse sobre la validez de esta denuncia.

\subsubsection{Denuncia de tratados constitutivos de organizaciones con sistemas de pro- tección de derechos humanos}

En ciertas ocasiones, y particularmente cuando la denuncia de los tratados de derechos humanos o sus protocolos facultativos no es viable o es insuficiente para impedir que los órganos creados por tales tratados supervisen a los Estados en materia de derechos humanos, los Estados podrían considerar denunciar los tratados constitutivos de las organizaciones que han previsto sistemas de protección de derechos humanos, lo que implicaría dejar de ser un Estado Miembro de la Organización de las Naciones Unidas (ONU), la Organización de los Estados Americanos (OEA), el Consejo de Europa (COE) o la Unión Africana (UA). Vale decir que todas estas organizaciones incluyen la protección de los derechos humanos entre sus propósitos fundamentales, al punto que una denuncia a sus tratados constitutivos tendría serios efectos en la protección de derechos humanos en el Estado denunciante.

El primer antecedente de esta naturaleza constituye la denuncia de Japón a la Sociedad de las Naciones (conocida también como Liga de las Naciones), ocurrida en marzo de 1933 luego de que la Sociedad ordenara el retiro de Japón en Manchuria. Pero no podría decirse que la Sociedad de las Naciones tenía un procedimiento de protección de derechos humanos, por lo que no hace falta detenernos en este ejemplo. Lo menciono simplemente porque el tratado constitutivo de la Organización de las Naciones Unidas, sucesora de la Sociedad de las Naciones, no contiene una cláusula de denuncia y es posible que el antecedente de Japón haya motivado a los redactores de la Carta de la ONU a omitir deliberadamente la posibilidad de denunciar este tratado para preservar su universalidad. 
Con posterioridad a la adopción de la Carta de la ONU y la Declaración Universal de Derechos Humanos, podría mencionarse el caso de Siria, que en 1958 se unió a Egipto para formar la República Árabe Unida. Egipto y Siria fueron Miembros originales de las Naciones Unidas y luego la República Árabe Unida continuó como un solo Estado Miembro hasta 1961. Así, tampoco constituye un verdadero caso de denuncia, pues Siria reasumió la condición de Estado independiente y simultáneamente su calidad de Estado Miembro separado.

En 1965, Indonesia intentó denunciar la Carta de la ONU como reacción a un conflicto con la Federación de Malasia, que iba a pasar a ser parte del Consejo de Seguridad de la Organización. Indonesia se alejó de la Organización por casi un año, pero luego reasumió sus obligaciones por lo que el caso se ha interpretado no como una denuncia, sino como una interrupción de colaboración de Indonesia con la ONU. No resulta extraño que hasta ahora no existan casos de Estados que hayan denunciado al tratado constitutivo de la Organización de las Naciones Unidas, en tanto la Carta de la ONU no contiene una cláusula expresa que permita su denuncia.

Vale también analizar lo sucedido con el Consejo de Europa. El Convenio Europeo para la Protección de los Derechos Humanos y de las Libertades Fundamentales, de 1950, fue objeto de una denuncia el 12 de diciembre de 1969, por parte de Grecia. La denuncia está permitida por el Artículo 58 del Convenio y se hizo efectiva, según las disposiciones del mismo Convenio, el 13 de junio de 1970. Si bien este caso podría analizarse en la sección relativa a la denuncia de tratados que permiten expresamente la denuncia, lo he incluido en esta sección en tanto una denuncia al Convenio Europeo de Derechos Humanos implicó también separación del Consejo de Europa. De hecho, la denuncia de Grecia estuvo acompañada por denuncias al Primer Protocolo al Convenio Europeo así como al Estatuto del Consejo de Europa. El artículo 7 del Estatuto del Consejo de Europa permite que cualquier miembro se retire del Consejo notificando su decisión al Secretario General.

Esta denuncia fue consecuencia de la inminente expulsión de Grecia del Consejo de Europa $^{65}$ en aplicación del artículo 8 del Convenio, a raíz de los hechos ocurridos en el marco de la llamada "Revolución de los Coroneles" que provocaron que varios Estados Parte del Convenio Europeo -particularmente países escandinavos ${ }^{66}$ - presentaran comunicaciones interestatales contra Grecia en el marco de las cuales la Comisión Europea de Derechos Humanos condenó a Grecia por cometer graves actos

65 La Asamblea Parlamentaria del Consejo de Europa había declarado ya que Grecia no cumplía las condiciones para ser un Estado Parte del Consejo de Europa y recomendado que el Consejo de Ministros considere su expulsión. 66 Council of Europe. European Commision of Human Rights. "The Greek Case". 
de tortura, entre otras graves violaciones de derechos humanos. Vale recordar que en ese entonces Grecia no era un Estado democrático, pues en 1967 una junta militar dio un golpe de Estado duramente criticado por el Consejo de Europa. La denuncia de Grecia al Estatuto del Consejo de Europa y al Convenio Europeo de Derechos Humanos restó toda legitimidad al régimen militar y finalmente la presión internacional condujo a la restauración de la democracia en Grecia en 1974. En noviembre de ese mismo año, Grecia retornó al régimen del Sistema Europeo de Protección de Derechos Humanos. El ejemplo de Grecia muestra que los Estados europeos fueron capaces de generar una presión política suficiente para dejar sin efecto una denuncia al Convenio Europeo de Derechos Humanos y lograr que un Estado se reincorpore al Consejo de Europa.

Desde 1969, ningún Estado Parte del Convenio Europeo de Derechos Humanos ha vuelto a ejercer su derecho de denuncia. No obstante, a partir de 2013 se volvió evidente que el gobierno del Reino Unido empezó a considerar seriamente su retiro del sistema europeo de derechos humanos. Un particular detonante de esta decisión constituyeron las decisiones del Tribunal Europeo que impiden al Reino Unido deportar a supuestos terroristas debido a su fundado temor de ser sometidos a torturas en su país de origen.

El partido de gobierno en el Reino Unido ha considerado derogar el Human Rights Act, norma que incorpora a la legislación británica el Convenio Europeo de Derechos Humanos. La propuesta es reemplazar esta norma por una carta de derechos británica que "rompa el lazo formal entre los tribunales británicos y el Tribunal Europeo de Derechos Humanos". Si bien la propuesta existe formalmente en el Parlamento, su consideración continúa siendo postergada. En el sistema regional africano, el único precedente constituye la denuncia de Marruecos a la Organización para la Unidad Africana (OUA) en 1984. La denuncia estaba expresamente permitida por la Carta de la OUA. ${ }^{67}$ Esta denuncia no estuvo vinculada con críticas a Marruecos en materia de derechos humanos sino que fue una respuesta a la decisión de la cumbre de la Organización para la Unidad Africana que se está celebrando en Addis Abeba, de permitir que la República Árabe Saharaui Democrática (RASD) ocupe un asiento en la cumbre. Hasta la fecha, Marruecos es el único Estado que no forma parte de la Unión Africana (UA), organización que desde el 2001 reemplazó a la Organización para la Unidad Africana y que reúne a 54 estados africanos. A pesar del precedente de Marruecos, los redactores del Acuerdo Constitutivo de la Unión Africana decidieron incluir expresamente la facultad de denunciar el tratado. ${ }^{68}$

67 Carta de la Organización para la Unidad Africana, artículo 32. 68 Acuerdo Constitutivo de la Unión Africana, artículo 31. 
En el sistema interamericano no existen antecedentes de denuncia a la Carta de la OEA, a pesar de que este tratado constitutivo sí contiene una cláusula expresa de denuncia. ${ }^{69}$ Ciertos Estados han amenazado con retirarse de la OEA, sin que tales amenazas se hayan materializado. Así, Nicaragua amenazó con dejar la organización como reacción a una resolución adoptada en 2010 por el Consejo Permanente de la Organización respecto del conflicto entre Nicaragua y Costa Rica, y desde 2011 Ecuador ha amenazado constantemente con "salir" del Sistema Interamericano de Derechos Humanos como reacción a decisiones de la Comisión Interamericana de Derechos Humanos que han resultado incómodas para el gobierno de Rafael Correa. A pesar de las amenazas, y aunque el tratado de la Organización lo permite, una denuncia a la Carta de la OEA sería un hecho sin precedentes en la historia de este sistema regional. A continuación nos referiremos específicamente al caso de Ecuador.

\subsubsection{La eventual denuncia de Ecuador a los Tratados del Sistema Interameri- cano de Derechos Humanos}

A partir de decisiones de la Comisión Interamericana de Derechos Humanos cuestionando el cumplimiento del Estado ecuatoriano con sus obligaciones en materia de derechos humanos, el gobierno de Rafael Correa empezó a amenazar de manera pública y reiterada con "salir" del Sistema Interamericano de Derechos Humanos. En particular, las decisiones de la Comisión respecto del caso "El Universo", ${ }^{70}$ los informes de la Relatoría Especial para la Libertad de Expresión y las medidas cautelares para proteger a personas condenadas a prisión por presentar denuncias contra el primer mandatario ${ }^{71}$ entre otras, resquebrajaron la relación entre el Estado de Ecuador y la Comisión. Las amenazas también pudieron estar catalizadas por la decisión de Venezuela de denunciar la Convención Americana sobre Derechos Humanos en septiembre de 2012. No sorprende que esta denuncia haya ocurrido al mismo tiempo en el que el Estado de Ecuador y otros Estados de la OEA reiteraban su intención de avanzar hacia la universalización del Sistema Interamericano de Derechos Humanos, y sin embargo no existió pronunciamiento alguno por parte de Ecuador lamentando este evidente retroceso en la universalización del sistema. Mientras el Canciller de Ecuador daba una gira por catorce Estados de la región para motivar a que los Estados que aún no lo han hecho, ratifiquen la Convención Americana, Venezuela de-

\footnotetext{
69 El artículo 143 de la Carta de la OEA dispone: "Esta Carta regirá indefinidamente, pero podrá ser denunciada por cualquiera de los Estados miembros, mediante comunicación escrita a la Secretaría General, la cual comunicará en cada caso a los demás las notificaciones de denuncia que reciba. Transcurridos dos años a partir de la fecha en que la Secretaría General reciba una notificación de denuncia, la presente Carta cesará en sus efectos respecto del Estado denunciante, y éste quedará desligado de la Organización después de haber cumplido con las obligaciones emanadas de la presente Carta".

70 CIDH. MC 406/11 - Emilio Palacio, Carlos Nicolás Pérez Lapentti, Carlos Pérez Barriga y César Pérez Barriga, Ecuador; CIDH. Informe No. 66/15. Petición 1436-11. Admisibilidad. Emilio Palacio Urrutia y otros. Ecuador. 27 de octubre de 2015. 71 CIDH. MC 30/14 - Fernando Alcibíades Villavicencio Valencia y otros, Ecuador.
} 
nunciaba la Convención sin que el Canciller realice gestión alguna para evitar que la denuncia se haga efectiva. Los silencios y omisiones podrían estar relacionados con la posibilidad de que Ecuador siga los pasos de Venezuela.

En todo caso, las autoridades ecuatorianas no han explicado si están considerando una denuncia a la Convención Americana sobre Derechos Humanos o una denuncia a la Carta de la OEA, por lo que examinaré brevemente ambas posibilidades. Ante la posibilidad de que el Estado denuncie la Convención Americana, es necesario primero recordar que esa denuncia no tendría efectos retroactivos. El artículo 78.2 de la Convención establece que la denuncia "no tendrá el efecto de desligar al Estado parte interesado de las obligaciones contenidas en esta Convención en lo que concierne a todo hecho que, pudiendo constituir una violación de esas obligaciones, haya sido cumplido por él anteriormente a la fecha en la cual la denuncia produce efecto". A través de este artículo, los Estados pretendieron asegurarse de que no se utilice a la denuncia de la Convención como un pretexto para evadir la responsabilidad ante un evidente incumplimiento de las disposiciones de la Convención. Así, toda violación de derechos humanos ocurrida durante la vigencia de la Convención en Ecuador, seguirá sometida al escrutinio de la Comisión y la Corte Interamericanas.

Segundo, en virtud del inciso primero del artículo 78 de la Convención, esa eventual denuncia recién se haría efectiva un año después de que sea notificada al Secretario General de la Organización. El preaviso de un año está contemplado con el propósito de que durante este plazo el Estado pueda reconsiderar su decisión y retirar la denuncia antes de que se haga efectiva. El reciente caso de la denuncia de Venezuela a la Convención demuestra, sin embargo, que ni los Estados, ni la sociedad civil fueron capaces de generar una presión internacional suficiente para impedir que la denuncia se haga efectiva transcurrido el año de preaviso.

Tercero, dado que la Comisión es un órgano principal de la organización según los artículos 106 y 53 de la Carta de la OEA, mientras que la Corte es un órgano creado por la Convención Americana, la denuncia de la Convención Americana implicaría únicamente que la Corte perdería competencia para pronunciarse sobre hechos ocurridos en Ecuador con posterioridad a que se haga efectiva la denuncia, pero seguiría teniendo competencia en casos de violaciones a los derechos humanos ocurridas antes de que se haga efectiva la denuncia. Adicionalmente, el Estado estaría obligado a cumplir las sentencias de la Corte dictadas antes de que la denuncia se haga efectiva.

Por su parte, la Comisión seguiría siendo competente para conocer violaciones de derechos humanos ocurridas en Ecuador, tanto a través del procesamiento de peticiones, casos y medidas cautelares como a través de las distintas facultades que aplica 
la CIDH para supervisar la situación de derechos humanos en los Estados miembros. Respecto de hechos ocurridos con posterioridad a que se hiciera efectiva una eventual denuncia, la Comisión se pronunciará sólo con base en la Declaración Americana de Derechos y Deberes del Hombre, y no con base en la Convención. Cabe aclarar que no importa la fecha en la que se presenten los casos, sino la fecha en la que hayan ocurrido los alegados hechos violatorios de derechos humanos. Así, peticiones presentadas con posterioridad a que se haga efectiva la denuncia, todavía podrían ser tramitadas a la luz de las obligaciones del Estado bajo la Convención Americana, y serían susceptibles de ser conocidas por la Comisión y la Corte Interamericanas.

En consecuencia, mientras Ecuador continúe siendo un Estado miembro de la OEA, aunque no sea un Estado Parte de la Convención, la Comisión Interamericana continuará cumpliendo con su mandato de promoción y supervisión de la situación de derechos humanos en Ecuador, y tramitando peticiones, casos y medidas cautelares. La jurisprudencia y práctica del sistema interamericano han reconocido que la Declaración Americana es fuente de obligaciones legales para los Estados miembros de la OEA, incluidos, en particular, los que no son parte de la Convención Americana. Además, aquellas normas de la Convención Americana que han pasado a formar parte del derecho consuetudinario internacional o que han alcanzado el status de normas iuscogens, seguirían siendo aplicables.

Ahora bien, la molestia del Estado ecuatoriano está dirigida hacia la Comisión y no hacia la Corte Interamericana. Por la estructura del sistema, una denuncia a la Convención Americana sólo tendría por efecto suspender la competencia contenciosa de la Corte, pero no respondería al propósito del Estado ecuatoriano de evitar la supervisión de la Comisión. Sólo una denuncia a la Carta de la OEA serviría a los propósitos de impedir que la Comisión supervise al Estado ecuatoriano. Según se analizó en la sección anterior, si bien la denuncia a la Carta de la OEA está prevista en el tratado, sería un acto sin precedentes en la historia del Sistema Interamericano de Derechos Humanos. En mi opinión, resulta improbable que las amenazas se materialicen. La denuncia a la Carta de la OEA requiere un preaviso de dos años, de forma tal que hasta que se haga efectiva toda violación de derechos humanos ocurrida durante el gobierno del Presidente Correa continuaría bajo la competencia de la Comisión. La denuncia a la Convención Americana no tiene el propósito buscado por el gobierno de evitar los pronunciamientos de la Comisión, y resulta inverosímil imaginar que el gobierno denuncie la Convención Americana justo cuando acaba de lograr que Patricio Pazmiño -juez de la Corte Constitucional que el Estado candidatizó y cuya cercanía al régimen es innegable- sea nombrado magistrado de la Corte Interamericana de Derechos Humanos. 


\subsection{Los límites derivados del derecho interno.}

Hasta aquí hemos analizado que, como consecuencia de la especial naturaleza de las obligaciones que los Estados asumen en virtud de la ratificación de tratados internacionales de derechos humanos, el derecho internacional de los derechos humanos establece límites a la facultad de los Estados de retirarse de estos tratados, incluso más allá de los límites derivados de Convención de Viena sobre el Derecho de los Tratados. También vimos que existen muy pocos casos de denuncias de tratados de derechos humanos, y que los organismos de supervisión de los tratados de derechos humanos han llegado a desconocer tales denuncias por considerarlas contrarias al objeto y fin de los tratados. Adicionalmente, el derecho adjetivo y sustantivo de cada Estado Parte podría imponer límites adicionales a la facultad de denunciar tratados internacionales.

En el caso de Venezuela, la más reciente denuncia a un tratado internacional de derechos humanos, Ayala Corao ha expuesto cómo

La decisión del Gobierno de la República Bolivariana de Venezuela de denunciar la Convención Americana sobre Derechos Humanos (CADH), además de afectar la protección colectiva de los derechos de las víctimas ante el sistema regional interamericano, viola su propia Constitución en virtud de que ésta (i) le otorgó jerarquía y supremacía constitucional a los tratados relativos a los derechos humanos; (ii) incorporó a la CADH expresamente en su normativa dentro de los requisitos internos que cumplir en los estados de excepción; (iii) consagró el derecho de protección internacional de los derechos humanos mediante el sistema de peticiones individuales previsto en los tratados sobre la materia; (iv) consagró en el derecho interno el principio de progresividad de los derechos humanos conforme a los tratados sobre la materia; y (v) estableció a los derechos humanos como un principio rector de las relaciones internacionales del Estado. ${ }^{72}$

Un ejercicio similar podría realizarse a la luz del derecho constitucional ecuatoriano, a pesar de que nuestra Constitución no consagra, como la de Venezuela, el derecho de petición internacional. La Constitución de 2008 otorga una jerarquía privilegiada a los tratados internacionales de derechos humanos y los incorpora al bloque de constitucionalidad. Según el artículo 424, los tratados pueden prevalecer sobre cualquier norma jurídica, incluso por sobre la Constitución, bajo la condición de que reconozcan derechos más favorables a los contenidos en la Constitución. Adicionalmente, en

72 Carlos Ayala Corao. "Inconstitucionalidad de la denuncia de la Convención Americana sobre Derechos Humanos por Venezuela". Anuario de Derecho Constitucional Latinoamericano (2013). 
virtud del artículo 417 de la Constitución, en el caso de los tratados internacionales de derechos humanos son aplicables los principios pro ser humano, de no restricción de derechos, de aplicabilidad directa y de cláusula abierta. Y a la luz del numeral tercero del artículo 11 de la norma constitucional, los derechos y garantías establecidos en los instrumentos internacionales de derechos humanos son de directa e inmediata aplicación por y ante cualquier servidor público, administrativo o judicial, de oficio o a petición de parte.

Los tratados internacionales de derechos humanos se entienden incorporados a la Constitución de Ecuador por su pertenencia al bloque de constitucionalidad, e incluso tienen una jerarquía superior a la Constitución en tanto sus normas sean más favorables al ejercicio de los derechos; en consecuencia, tales tratados deben gozar de una rigidez normativa por lo menos equiparable a la de la Constitución. No podrían los tratados de derechos humanos a los que la Constitución hace referencia con tanta frecuencia desaparecer de la normativa ecuatoriana únicamente a voluntad del gobierno de turno.

Además, el numeral 8 del artículo 11 de la Constitución ecuatoriana consagra el principio de progresividad de los derechos. Según esta norma, el contenido de los derechos se desarrolla de manera progresiva a través de las normas, la jurisprudencia y las políticas públicas. De hecho, varias leyes, sentencias y planes emitidos en Ecuador hacen referencia explícita a tratados internacionales de derechos humanos de los que Ecuador es parte, incluyendo la Convención Americana. El citado artículo 11 menciona también que cualquier acción de carácter regresivo que disminuya, menoscabe o anule injustificadamente el ejercicio de los derechos, será inconstitucional.

El lenguaje es lo suficientemente amplio como para sostener que la denuncia de un tratado internacional de derechos humanos, acto claramente regresivo en materia de derechos, sería contraria a la Constitución. La protección de los derechos humanos hace parte de un régimen que siempre podrá ser ampliado, mas no restringido. La denuncia de un tratado de derechos humanos como la Convención Americana significaría una regresión inaceptable respecto de derechos protegidos de manera más favorable en la Convención que en la Constitución, como por ejemplo el derecho a la libertad de expresión. También debemos prestar atención al procedimiento a través del cual se perfecciona la denuncia. Si bien a nivel internacional basta con que la denuncia sea debidamente notificada al Secretario General de la organización en cuestión, y tal notificación en Ecuador dependería únicamente de la Cancillería, no podemos asumir que bastaría la voluntad del Presidente de la República para que se materialice la denuncia. En un Estado constitucional y democrático, estos actos no se realizan sin consulta a los otros poderes del Estado. De hecho, varios Estados han 
establecido sistemas de chequeos y balances respecto de la decisión de denunciar tratados internacionales ${ }^{73}$.

La lógica nos llevaría a asumir que, por lo menos, el proceso de denuncia debe ser similar al proceso de ratificación de un tratado internacional de derechos humanos. La ratificación de los tratados internacionales es una de las atribuciones que la Constitución asigna al Presidente de la República (artículo 147). Según la norma constitucional, si bien corresponde al Presidente de la República suscribir o ratificar tratados internacionales, este está obligado a informar de manera inmediata a la Asamblea Nacional sobre todos los tratados que suscriba (artículo 418). La Asamblea Nacional, a su vez, está facultada para aprobar o improbar los tratados internacionales en los casos que corresponda (artículo 120). Los tratados internacionales que se refieran a derechos y garantías establecidos en la Constitución están entre los casos que requieren una ratificación por parte de la Asamblea Nacional (artículo 419).Pero antes de la aprobación legislativa, es necesario un dictamen previo y vinculante de constitucionalidad por parte de la Corte Constitucional (artículo 438).

Bajo el principio de que las cosas se deshacen como se hacen, la denuncia de un tratado internacional de derechos humanos debería pasar por un procedimiento de control previo por parte de la Corte Constitucional y ratificación de la decisión de denunciar por parte de la Asamblea Nacional. No obstante, la Constitución contiene normas expresas para el procedimiento de denuncia. Según el artículo 420 de la Constitución, "la denuncia de un tratado aprobado corresponderá a la Presidenta o Presidente de la República”. Si leyéramos este artículo aisladamente, podríamos pensar que el Presidente está plenamente facultado para denunciar tratados internacionales de derechos humanos. No obstante, según el artículo 419 numeral cuarto de la Constitución, la denuncia de los tratados internacionales que se refieran a derechos y garantías establecidos en la Constitución requiere la aprobación previa de la Asamblea Nacional. Así, una denuncia a un tratado internacional debidamente notificada al Secretario General por parte de Cancillería sería inconstitucional si no fue previamente aprobada por la Asamblea. La Constitución no prevé un examen previo de

\footnotetext{
73 Así, por ejemplo, en España los artículos 96.2 y 94.1.c de la Constitución, establecen que la denuncia de los tratados sobre derechos y deberes fundamentales requieren previa autorización o aprobación por parte del legislativo; el artículo 57 de la Constitución de Perú también exige autorización previa del Congreso respecto de los tratados de carácter humanitario; el artículo 142 de la Constitución de Paraguay establece que los tratados relativos a derechos humanos no podrán ser denunciados sino por los procedimientos que rigen para la enmienda constitucional; mientras que en Argentina los tratados sólo pueden ser denunciados por el ejecutivo si tal decisión cuenta con la aprobación de las dos terceras partes de la totalidad de los miembros de cada Cámara del Congreso de la Nación; el artículo 90 de la Constitución Cubana, atribuye al Consejo de Estado ratificar y denunciar tratados internacionales; Costa Rica autoriza en cambio a la Corte Suprema de Justicia, mediante el artículo 10, conocer de las consultas sobre proyectos de reforma constitucional, de aprobación de convenios o tratados internacionales y de otros proyectos de ley, según se disponga en la ley.
} 
constitucionalidad de la decisión de denunciar un tratado internacional de derechos humanos, lo que demuestra que los constituyentes no lograron comprender la gravedad de un acto de esta naturaleza. La facultad de ratificar tratados internacionales de derechos humanos es un acto ordinario de las relaciones internacionales, mientras que la facultad de denunciar esos mismos tratados, por su gravedad, debería estar sometida a un régimen igual o más estricto que el aplicable para su ratificación.

Finalmente, a la luz del concepto de bloque de constitucionalidad, también podría alegarse que los tratados internacionales de derechos humanos suscritos por Ecuador en 2008, cuando la Constitución de Ecuador se sometió a referéndum, fueron también aprobados por la ciudadanía como parte de ese referéndum. Si entendemos que el referéndum constituyente incluyó la aprobación de los tratados internacionales de derechos humanos a los que con tanta frecuencia se refiere la Constitución, podemos sostener que resulta aplicable la disposición final del artículo constitucional 420 que señala que "en caso de denuncia de un tratado aprobado por la ciudadanía en referéndum se requerirá el mismo procedimiento que lo aprobó". Admito que el argumento de que una denuncia de los tratados internacionales de derechos humanos requiere un referéndum no es el más contundente, pero tampoco es descartable. Ante la eventualidad de que Ecuador pretenda desvincularse de los tratados y organismos internacionales de derechos humanos, debemos estar preparados para utilizar todas las herramientas que la Constitución nos ofrece para evitar un retroceso de esa magnitud en la protección de nuestros derechos.

\section{Reflexiones finales sobre la denuncia de un tratado internacional de derechos humanos.}

Lo analizado hasta aquí nos permite concluir que la denuncia de tratados internacionales de derechos humanos no constituye un acto ordinario de las relaciones internacionales de un Estado. Por el contrario, se trata de un acto revestido de límites derivados tanto del derecho internacional como del derecho interno de los Estados, dirigidos a impedir que un acto tan regresivo para la protección de los derechos humanos se materialice.

Los tratados de derechos humanos no son uniformes respecto de sus cláusulas de denuncia. Están los que prevén expresamente la denuncia, otros someten la denuncia a una serie de condiciones, algunos solamente permiten denunciar las cláusulas jurisdiccionales facultativas, y otros más guardan silencio sobre la denuncia. Algo similar sucede con los tratados constitutivos de organizaciones internacionales o regionales que han previsto sistemas de protección de derechos humanos. Los tratados constitutivos de organizaciones regionales a nivel interamericano, africano y euro- 
peo permiten la denuncia sujeta a una serie de condiciones temporales y financieras, mientras que la Carta de la ONU no contiene una cláusula de denuncia, lo que ha sido interpretado como una cuestión deliberada que responde a la intención de dar perpetuidad a esta organización.

Tampoco es posible identificar una práctica uniforme de los organismos de supervisión de los tratados de derechos humanos en relación con la facultad de denunciar tratados. Si bien, como se mencionó, la Comisión Africana parece reconocer un derecho implícito de denuncia, la tendencia de los organismos del sistema universal y del sistema interamericano sugiere que las denuncia a los tratados de derechos humanos sólo son posibles en cuanto esa facultad se encuentre explícitamente prevista por el tratado en cuestión. Los casos de denuncias a instrumentos que guardan silencio sobre la facultad de denunciar el tratado como un todo o sus procedimientos jurisdiccionales facultativos, han sido interpretados como no válidos y contrarios al objeto y fin de tales tratados.

La denuncia de un tratado de derechos humanos no puede equipararse a la denuncia de cualquier otro tratado o acuerdo internacional. Un acto de esta naturaleza genera que los ciudadanos perdamos una importante instancia de protección de derechos humanos. A pesar de todas las críticas que puedan realizarse a los sistemas interamericano y universal de protección de derechos humanos, es indudable que varias víctimas han encontrado en tales sistemas una fuente de justicia y reparación que sus Estados les habían negado. La denuncia de un tratado internacional de derechos humanos es una medida claramente regresiva para la protección de esos derechos, que contradice el principio de su desarrollo progresivo y disminuye el estándar de protección de los derechos humanos alcanzado a nivel internacional. Además, viola el principio de buena fe en el cumplimiento de los tratados, según el cual los pactos deben honrarse.

Adicionalmente, la denuncia de un tratado internacional de derechos humanos perjudica los esfuerzos realizados hacia la ratificación universal de los principales tratados de derechos humanos en el mundo. Los Estados miembros de organizaciones internacionales como la OEA y la ONU han adoptado una serie de resoluciones comprometiéndose a avanzar en la universalización de los sistemas de protección de derechos humanos a través de la firma y ratificación de todos los instrumentos de derechos humanos por parte de todos los Estados miembros. La denuncia de un tratado de este tipo no sólo constituye un retroceso en la universalización sino que debilita la integridad de los sistemas de protección de derechos humanos. 
La mera amenaza o rumor de denuncia de estos tratados ya debilita al sistema de protección de derechos y afecta su eficacia. Por ejemplo, en el caso de Ecuador, el gobierno del Presidente Correa ha amenazado reiteradamente con "salir" del Sistema Interamericano de Derechos Humanos, lo que se ha traducido una actitud timorata por parte de la Comisión y la Corte Interamericanas respecto de Ecuador. Tal parecería que estos organismos están tratando de evitar que sus decisiones incomoden al gobierno al punto de que el Estado abandone la OEA o denuncie la Convención Americana, y esta actitud evasiva ya ha perjudicado la posibilidad de que víctimas de violaciones de derechos humanos ocurridas en Ecuador obtengan justicia a nivel interamericano.

La historia muestra que sólo un número muy reducido de Estados ha llegado a denunciar tratados de derechos humanos, y que algunas de esas denuncias han perdido vigencia pues los Estados han decidido regresar a los sistemas de protección de derechos humanos, lo que confirma que cuando de tratados internacionales de derechos humanos se trata, la denuncia no constituye un acto ordinario de las relaciones internacionales de un Estado.

Lamentablemente, el recuento de los escasos casos de denuncias de tratados internacionales de derechos humanos también evidencia que, con excepción de Europa, la presión internacional no ha sido suficiente para impedir que tales denuncias se hagan efectivas. Las denuncias de los tratados internacionales por parte de los Estados del Caribe han quedado casi en el olvido.

No existen actualmente mayores esfuerzos dirigidos a reincorporar estos Estados al régimen de protección universal o interamericano de derechos humanos. La reciente denuncia a la Convención Americana por parte de Venezuela, si bien no pasó desapercibida, no fue capaz de motivar una condena internacional lo suficientemente fuerte como para que el Estado recapacite.

La denuncia de un tratado internacional de derechos humanos debería afectar seriamente la reputación internacional del Estado denunciante, debería tener consecuencias en la cooperación internacional e incluso en el acceso a acuerdos comerciales. Mientras esto no suceda, la vergüenza pública internacional no será suficiente para impedir que un Estado reconsidere su decisión de denunciar un tratado internacional de derechos humanos.

La denuncia de los tratados internacionales de derechos humanos sin duda pone a prueba el rol de los Estados como garantes del sistema internacional de protección de derechos humanos. Hasta ahora, sólo los Estados Miembros del Consejo de Eu- 
ropa pasaron esa prueba. El caso de Grecia demostró que un Estado Miembro del Consejo no puede tomarse el riesgo de denunciar el Convenio europeo de protección de derechos humanos sin correr el riesgo de ser expulsado del Consejo de Europa. El caso de Venezuela demuestra que los Estado de la OEA han fallado en su rol como garantes del sistema.

Ante la posibilidad de que la comunidad internacional falle al momento de impedir una eventual denuncia a los tratados internacionales de derechos humanos, la sociedad civil debe buscar los mecanismos para impedir que tal denuncia se haga efectiva. Los ciudadanos somos los beneficiarios de los tratados internacionales de derechos humanos, y como tales no debemos tolerar un acto que pretenda despojarnos de la protección internacional que esos tratados nos brindan.

Los Estados siempre tratarán de justificar su decisión de denunciar un tratado internacional de derechos humanos en el ejercicio de su soberanía, en la politización o ineficacia de los organismos de supervisión consagrados por esos tratados, o en su intervención en decisiones soberanas internas. Con cada vez más frecuencia, las decisiones de los organismos jurisdiccionales y cuasi jurisdiccionales de protección de derechos humanos están dando lugar a impasses entre dichos organismos y los Estados o sus tribunales internos. Aun cuando respecto de algunas de estas críticas podamos coincidir con el Estado, como beneficiarios de los tratados de derechos humanos, los ciudadanos tenemos derecho a oponernos a su denuncia e impedir que, sin que nos consulten, puedan despojarnos de la protección internacional cuya construcción sólo fue posible a raíz de graves y sistemáticas violaciones de derechos humanos.

Sólo la vergüenza pública de los Estados generada a partir de los hechos ocurridos en las dos guerras mundiales y las graves violaciones de derechos humanos perpetradas durante las dictaduras del siglo pasado pudo llevar a la construcción de un régimen internacional de protección de derechos humanos. Los sistemas de protección internacional de derechos humanos no son perfectos, pero son lo que se ha logrado hasta el momento. En honor a las víctimas de violaciones de derechos humanos ocurridas en el pasado, los ciudadanos debemos estar alertas y listos para activar todos los mecanismos internos e internacionales disponibles para impedir que se menoscabe nuestro derecho a obtener justicia en instancias internacionales cuando los Estados omitan su deber de proteger y garantizar nuestros derechos. 


\section{Bibliografía}

Ávila Hernández, F., "Algunas consideraciones jurídicas sobre la denunci de la Convención Americana de Derechos Humanos por Venezuela", FRONESIS, Vol. 20, No. 2, 2013, 206-217.

Ayala Corao, C. (2013), "Inconstitucionalidad de la denuncia de la Convención Americana sobre Derechos Humanos por Venezuela", Anuario de derecho constitucional latinoamericano año XIX, Bogotá, 2013, 43-79, disponible en: http:// www.corteidh.or.cr/tablas/r32197.pdf (acceso: 22/02/2016).

Concepcion, N., “The Legal Implications of Trinidad E Tobago's Withdrawal from the American Convention on Human Rights", American University International LawReview 16, No. 3, 2001, 847-890.

Crawford, J., E Vaughan, L., "The Denunciation of Human Rights Treaties”, British Year Book of International Law, 2008, pp. 156-157.

Helfer, L., "Overlegalizing Human Rights: International Relations Theory and the Commonwealth Caribbean Backlash Against Human Rights Regimes", Columbia Law Review, Vol. 102, Vanderbilt Public Law Research Paper No. 06-05, 2002.

Huneeus, Alexandra, "Courts Resisting Courts: Lessons from the Inter-American Court's Struggle to Enforce Human Rights, Cornell: Cornell Int'l L.J., 2000.

Márquez Luzardo, C., "La denuncia de la Convención Americana sobre Derechos Humanos y otros casos paradigmáticos. Los precedentes de: Trinidad y Tobago; Perú y Venezuela", Cuestiones Jurídicas VIII (Enero-Junio), 2014.

Naldi, G.; Magliveras, K., "Human Rights and the Denunciation of Treaties and Withdrawal from International Organisations, XXXIII Polish Yearbook of International Law, 2013.

Ochoa Jimenez, M., "La protección de los derechos humanos en venezuela frente a la denuncia de la convención americana sobre derechos humanos", Revista Latinoamericana de Derechos Humanos, Norteamérica, 25, 2013, http://www. revistas.una.ac.cr/index.php/derechoshumanos/article/view/6125.

Riquelme Cortado, Rosa, Las Reservas a los tratados; lagunas y ambigüedades del Régimen de Viena, Murcia, 2004, 
Schiffrin, Natalia, "Jamaica Withdraws the Right of Individual Petition Under the International Covenant on Civil and Political Rights", The American Journal of International Law, Vol. 92, No. 3 (Jul., 1998), pp. 563-568.

Quigley, J., “The United States' Withdrawal from International Court of Justice Jurisdiction in Consular Cases: Reasons and Consequences", 19 Duke Journal of Comparative $\mathcal{E}$ International Law, 2009, pp. 263-306.

Yogesh, T., The Denunciation of Human Rights Treaties. British Yearbook of International Law79, 2008, pp. 86-193.

\section{Convenciones, cartas, protocolos y pactos}

Acuerdo Constitutivo de la Unión Africana

Carta de la Organización para la Unidad Africana

Convención Americana sobre Derechos Humanos

Convención contra la Tortura y Otros Tratos o Penas Crueles, Inhumanos o Degradantes

Convención de Kampala sobre Desplazados Internos

Convención Interamericana contra el Racismo, la Discriminación Racial y Formas Conexas de Intolerancia

Convención Interamericana para la Eliminación de Todas las Formas de Discriminación contra las Personas con Discapacidad

Convención Internacional para la protección de todas las personas contra las desapariciones forzadas

Carta Africana sobre Derechos Humanos y de los Pueblos y su Protocoloç

Convención Sobre la Eliminación de Todas las Formas de Discriminación Contra la Mujer

Convención sobre los Derechos del Niño

Convención sobre los Derechos de las Personas con Discapacidad 
Protocolo Facultativo Sobre la Participación de los Niños en los Conflictos Armados

Pacto Internacional de Derechos Civiles y Políticos

Protocolo Facultativo de la Convención contra la Tortura y Otros Tratos o Penas Crueles, Inhumanos o Degradantes

Protocolo Facultativo de la Convención Sobre los Derechos de las Personas con Discapacidad

Protocolo Facultativo de la Convención Sobre los Derechos del Niño Relativo a la Venta de Niños, la Prostitución Infantil y la Utilización de Niños en la Pornografía

Protocolo Facultativo del Pacto Internacional de Derechos Económicos, Sociales y Culturales

Protocolo Facultativo Primero del Pacto Internacional de Derechos Civiles y Políticos

Protocolo Facultativo de la Convención Sobre los Derechos del Niño Sobre la Participación de los Niños en los Conflictos Armados Sentencias, informes, opiniones y comunicados

\section{$\underline{\text { Sentencias, informes, opiniones y comunicados }}$}

Alto Comisionado de las Naciones Unidas para los Derechos Humanos, "Continuidad de las obligaciones establecidas en los tratados internacionales de derechos humanos". Sub Comité. Resolución 1999/5, 25 de agosto de 1999.

Amnistía Internacional, Informe Anual de 1999, Pp. 332 y 333.

Amnistía Internacional, La ruptura de Venezuela con la corte regional de derechos humanos es "una afrenta a las víctimas", 13 septiembre 2012 CDH, Observación General No. 26, Comentarios generales adoptados por el Comité de los Derechos Humanos, Continuidad de las obligaciones, $66^{\circ}$ período de sesiones, U.N. Doc. HRI/GEN/1/Rev.7, 1997.

Caso "Rawle Kennedy vs. Trinidad y Tobago", Communication No. 845/1998, U.N. Doc. CCPR/C/74/D/845/1998, 2002.

., Comunicado de Prensa 64/2013, “CIDH manifiesta su profunda preocupación 
por efecto de la denuncia de la Convención Americana por parte de Venezuela", 10 de septiembre de 2013

Comunicado de Prensa 117/12, “CIDH lamenta decisión de Venezuela de denunciar Convención Americana sobre Derechos Humanos”, 12 de septiembre del 2012.

Coalición Internacional de Organizaciones por los Derechos Humanos en las Américas, Comunicado de Prensa: "Denuncia de Convención Americana sobre Derechos Humanos por Venezuela debilita protección de los derechos fundamentales de sus ciudadanos/as", 9 de septiembre de 2012.

Comisión Africana de Derechos Humanos, Civil Liberties Organization v. Nigeria, Comunicación No. 129/94, 1995.

Comisión Europea de Derechos Humanos, “Austria vs. Italy, Application No. 788/60", European Yearbook of Human Rights, (1961), vol. 4, pág. 140.

$\mathrm{CDH}$, Comentario General 24(13).

Comentario General 24(8).

Observación General No. 26, Comentarios generales adoptados por el Comité de los Derechos Humanos, Continuidad de las obligaciones, $66^{\circ}$ período de sesiones, U.N. Doc. HRI/GEN/1/Rev.7 (1997), párrafos 3-5.

Comité Judicial del Consejo Privado en Pratt E Morgan c. the Attorney General of Jamaica. 2 A.C.1. (1993).

Congreso de la República de Perú, Resolución Legislativa № 27401.

Consejo Económico y Social, Comisión de Derechos Humanos, $51^{\circ}$ período de sesiones, tema 18 del programa provisional: "Carta de fecha 10 de enero de 1995 dirigida al Presidente de la Comisión de Derechos Humanos por el Embajador, Encargado de negocios interino de la República Federativa de Yugoslavia ante la Oficina de las Naciones Unidas en Ginebra". E/CN.4/1995/130. 7 de febrero de 1995.

Consejo Económico y Social, Subcomisión de Prevención de Discriminaciones y Protección a las Minorías, resolución de la Subcomisión 1997/3: Situación de los derechos humanos en la República Popular Democrática de Corea. E-CN_4- 
SUB_2-RES-1997-3. 24a sesión, 21 de agosto de 1997.

Corte Internacional de Justicia, "Reservas a la Convención para la Prevención y Sanción del Delito Genocidio", Opinión Consultiva de 28 de mayo de1951.

Council of Europe, European Commision of Human Rights. "The Greek Case”.

Corte IDH, Asunto James y otros respecto Trinidad y Tobago.

. Caso Apitz Barbera y otros ("Corte Primera de lo Contencioso Administrativo") vs. Venezuela. Sentencia de 5 de agosto de 2008.

_., Caso Castillo Petruzzi y otros vs. Perú, Sentencia de 30 de mayo de 1999 (Fondo, Reparaciones y Costas).

Caso Caesar Vs. Trinidad y Tobago, Sentencia de 11 de marzo de 2005.

, Caso Hilaire, Constantine y Benjamin y otros Vs. Trinidad y Tobago, Sentencia de 21 de junio de 2002.

_., Caso Ivcher Bronstein Vs. Perú, Sentencia de 24 de septiembre de 1999.

_., Caso del Tribunal Constitucional Vs. Perú, Sentencia de 31 de enero de 2001 (competencia).

, Caso Loayza Tamayo Vs. Perú, Sentencia de 27 de noviembre de 1998 (Reparaciones y Costas).

Informe Anual de la Corte Interamericana de Derechos Humanos, 1998, OEA/ Ser.L/V/III.43 Doc. 11, págs. 35, 36 y 37.

., "Otros Tratados", Objeto de la Función Consultiva de la Corte (art. 64 Convención Americana sobre Derechos Humanos). Opinión Consultiva OC-1/82 del 24 de septiembre de 1982. Serie A No. 1.

., "El Derecho a la Información sobre la Asistencia Consular en el marco de las Garantías del debido proceso legal", Opinión Consultiva OC-16/99. 1 de octubre de 1999, solicitada por los Estados Unidos Mexicanos.

CIDH, MC 406/1 1 - “Emilio Palacio, Carlos Nicolás Pérez Lapentti, Carlos Pérez Barriga y César Pérez Barriga, Ecuador". 
Informe No. 66/15, "Petición 1436-11", Admisibilidad. Emilio Palacio Urrutia y otros. Ecuador. 27 de octubre de 2015.

MC 30/14 - Fernando Alcibíades Villavicencio Valencia y otros, Ecuador.

Ministerio del Poder Popular para las Relaciones Exteriores, República Bolivariana de Venezuela, "Nota 000125", Fecha 6 de septiembre de 2012.

Ministerio de Relaciones Exteriores de Costa Rica, Comunicado "Fortalecimiento SIDH" de 11 de septiembre de 2012 en el que el Canciller "deploró" la decisión de Venezuela de denunciar el Pacto de San José, y abogó porque Caracas pueda lo más pronto posible "reconsiderar la decisión" y adherirse nuevamente a la Convención Americana de Derechos Humanos.

OEA, Representación Permanente del Estado de Perú ante la OEA, “Posición del gobierno peruano ante los fallos de la Corte Interamericana de Derechos Humanos", 1 de julio de 1999.

ONU, Consejo Económico y Social. Sub-Commission on the Promotion and Protection of Human Rights, Commission of Human Rights, "Resolution 1999/5: Continuing of obligations under international human rights treaties", (E/ CN.4/2000/2; E/CN.4/Sub.2/1999/54). 31st meeting, 25 de agosto de 1999. República de Corea, Informe periódico de la República de Corea ante el Comité de Derechos Humanos (CCPR/C/1 14/Add.1).

República de Corea. Informe periódico de la República de Corea ante el Comité de Derechos Humanos (CCPR/C/PRK/2000/2).

Secretario General de la Organización de los Estados Americanos, "Comunicado de prensa", C-307/12.

Secretaría de Relaciones Exteriores, México, "México lamenta la decisión de denunciar a la Convención Americana sobre Derechos Humanos", Comunicado 250, 11 de septiembre de 2012, disponible en: http://saladeprensa.sre.gob. mx/index.php/comunicados/1771-250 (acceso: 22/02/2016).

Tribunal Constitucional de Perú, "Resolución del Pleno del 31 de agosto de 2009", EXP. N. ${ }^{\circ}$ 04063-2007-PA/TC.

Tribunal Europeo de Derechos Humanos, Soering vs. United Kingdom, Application No. 161, (1989) párrafo 87. 
Wemhoff vs. Germany, Application No. 1936/63 (1968), vol. 7

Ireland vs. United Kingdom, Application No. 5310/71, (1978), vol. 25.

Tribunal Supremo de Justicia de Venezuela (“TSJ”), Sentencia Nº 1939 de la Sala Constitucional del 2008. 